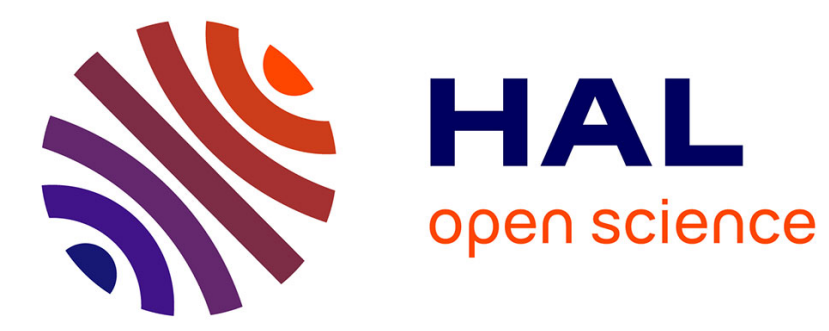

\title{
Numerical modelling of magma transport in dykes
}

\author{
Philippe Yamato, Romain Tartese, Thibault Duretz, Dave A. May
}

\section{To cite this version:}

Philippe Yamato, Romain Tartese, Thibault Duretz, Dave A. May. Numerical modelling of magma transport in dykes. Tectonophysics, 2012, 526-529, pp.97-109. 10.1016/j.tecto.2011.05.015 . insu00676693

\section{HAL Id: insu-00676693 https://hal-insu.archives-ouvertes.fr/insu-00676693}

Submitted on 16 Mar 2012

HAL is a multi-disciplinary open access archive for the deposit and dissemination of scientific research documents, whether they are published or not. The documents may come from teaching and research institutions in France or abroad, or from public or private research centers.
L'archive ouverte pluridisciplinaire HAL, est destinée au dépôt et à la diffusion de documents scientifiques de niveau recherche, publiés ou non, émanant des établissements d'enseignement et de recherche français ou étrangers, des laboratoires publics ou privés. 


\title{
Numerical modelling of magma transport in dykes
}

\author{
P. Yamato ${ }^{1,2, *}$, R. Tartèse ${ }^{1}$, T. Duretz ${ }^{2}$ and D. A. May ${ }^{2}$
}

Accepted for publication in: Tectonophysics (GeoMod2010 - special issue)

${ }^{1}$ Géosciences Rennes, CNRS UMR6118, Université de Rennes 1, 35042 Rennes, France

${ }^{2}$ ETH-Zurich, Sonneggstrasse 5, CH-8092 Zurich, Switzerland

*corresponding author: philippe.yamato@univ-rennes1.fr 


\section{Abstract}

The rheology and dynamics of an ascending pure melt in a dyke has been extensively studied in the past. From field observations, it is apparent that most dykes actually contain a crystalline load. The presence of a crystalline load modifies the effective rheology of such a system and thus the flow behaviour. Indeed, the higher density and viscosity of each crystal, compared to the melt, causes a decrease of the ascent velocity and modifies the shape of the velocity profile, from a typical Poiseuille flow, to a Bingham-type flow. A common feature observed in the field is the arrangement of crystals parallel or at a very low angle to the edge of the dyke. Such a structural arrangement is often interpreted as the result of magma flow, which caused the crystals to rotate and align within the flow direction, but this process remains unclear. Another issue related to the introduction of a crystalline load concerns the possibility for crystals to be segregated from a viscous granitic melt phase during magma ascent. This has never been investigated numerically let alone the implications that this process could have on magmatic differentiation. In this study, we examine the flow dynamics of a crystal bearing granitic melt ascending in a dyke via numerical models. In our models, both the crystal and melt phases are represented as highly viscous fluids in a Stokes regime. Our results reveal that the presence of crystals in the melt modifies the magma velocity profile across the dyke. Furthermore, we observe that whilst crystals continually rotate in the shear flow, over one period of revolution, their major axis have a high probability to be aligned parallel to the flow direction. Moreover, some experiments showed that the melt phase can effectively be squeezed out from a crystal-rich magma when subjected to a given pressure gradient range. This demonstrates that crystal-melt segregation in dykes during granitic magma ascent constitutes a viable mechanism for magmatic differentiation. 
Keywords: Dyke; Magma ascent; Numerical modelling; Crystal rotation; Magmatic differentiation.

\section{Introduction}

The processes related to magma ascent from source zones towards emplacement sites of magmatic intrusions in the upper crust constitutes a major subject of interest in Earth sciences, especially in terms of understanding intra-crustal differentiation. In particular, the mechanism leading to granitic melt migration towards the upper continental crust (represented by the "diapirism" and "dyking" end-members) has been controversially discussed throughout the $20^{\text {th }}$ century (see reviews by Clemens, 1998; Petford, 2003). Nevertheless, since the study of Clemens and Mawer (1992), it is now largely agreed that the most viable mechanism for the migration of magma, from the deep partial melting zone where they form, to the upper crust where they emplace, is dyking (e.g., Petford et al., 1994; Scaillet et al., 1996; Clemens and Petford, 1999; Clemens, 1998, 2003).

The rheology and the behaviour of a multiphase magma (i.e., composed of suspended crystals carried by a viscous medium) subject to a given pressure gradient is governed by the amount of crystals and their geometry (e.g., Bagdassarov and Dorfman, 1998). Here we do not consider the effect of gas bubbles because the processes that we study occur at a depth where volatiles are dissolved in the melt phase. When the amount of crystals is small, silicate melts are considered as Newtonian fluids and their behaviour follows the Einstein-Roscoe relations (Einstein, 1906; Roscoe, 1953). Above a critical solid fraction of suspended crystals, depending on their size, shape and distribution in the magma, the suspension can form a rigid skeleton (Philpotts et al., 1998), which introduces a yield stress in the magmatic suspension and thus results in an effective non-Newtonian rheology (e.g. Kerr and Lister, 1991). The volume of crystals at which the transition from a Newtonian to a non-Newtonian rheology 
occurs has been estimated somewhere between 15 and 50 vol.\% (Champallier et al., 2008; Hallot et al., 1996; Kerr and Lister, 1991; Petford and Koenders, 1998; Petford, 2003; Walsh and Saar, 2008). When the magma contains ca. 55\% of solid particles, only residual liquids can escape the rigid skeleton formed by crystals, an effect known as the "rigid percolation threshold" (Vigneresse et al., 1996). According to these authors, when ca. $75 \%$ of crystallization occurs, the entire system becomes totally locked, preventing further mechanical melt percolation from occurring.

Field observations of crystal arrangement in frozen dykes reveal that both their repartitions and their orientations are not random (e.g., Smith, 2002; Paterson, 2009; Chistyakova and Latypov, 2010). In many instances, the crystals are found to be orientated with their major axis parallel, or at a low angle, to the edges of the dyke following the magma flow direction. However, the processes of crystal re-orientation and of their spatial organisation acting during magma transport cannot be directly observed and thus have to be modelled. The rotation of solids immersed in a deforming viscous medium has been addressed in numerous analogue experiments (e.g., Arbaret et al., 1996, 2001; Marques and Burlini, 2008; Marques and Coelho, 2001, 2003; Van den Driessche and Brun, 1987; Willis, 1977) and numerical studies (Bons et al., 1996; Mandal et al., 2001; Marques et al., 2005a, 2005b; Samanta et al., 2002; Schmid, 2005). Also, observations of the crystal size distribution within dykes often show that the crystals are sorted by their size, increasing from the edges of the dyke to the centre (e.g., Nkono et al., 2006 and references therein). This can be attributed to their mechanical segregation during the magmatic transport, a phenomenon known as the "Bagnold effect" (e.g., Bagnold, 1954; Barrière, 1976; Bhattacharji, 1967; Komar, 1972a, 1972b). Besides the fact that these two phenomena should occur coevally during crystalbearing magma transport in dykes, this complex mechanism remains poorly constrained. Numerous experimental (e.g., Bagdassarov and Dorfman, 1998) and numerical (e.g., 
Deubelbeiss et al., 2010) studies have been undertaken on magmatic suspension containing particles. However, they mainly addressed the issue of quantifying the effective viscosity of the crystal-melt system and the related rheological consequences, with an emphasis on volcanism (Caricchi et al., 2007; Costa et al., 2007; Dingwell, 1996; Melnik and Sparks, 1999; Papale, 1999, Taisne and Jaupart, 2011).

Finally, another fundamental aspect of magma dynamics is the capacity of crystal-melt segregation to occur during magma ascent in dykes, which has important consequences for magmatic differentiation processes. Crystal-melt fractionation is controlled by factors such as the density difference between the solid and liquid phases, the viscosity of the melt phase, the crystal size and the dynamics of the system. In granitic rocks, such a process is considered to be difficult to initiate, because of (i) the common belief that granitic melts are highly viscous and (ii) the lack of a sufficiently high density difference between the minerals and the residual liquid. Granitic melt viscosities are in the range $10^{4}-10^{6}$ Pa.s (e.g., Scaillet et al., 1998; Clemens 1998), and the density difference between the melt and common crystals is typically in the range of $200-400 \mathrm{~kg} \cdot \mathrm{m}^{-3}$.

To our knowledge, numerical modelling has not been used to study crystal-melt segregation processes that might take place in dykes at depth. In order to address this issue, we propose to use a fluid dynamic description of creeping flow (Stokes) to represent both the crystal and melt phases in one coupled system. We first verify that the numerical method developed can reproduce the known behaviour of highly viscous, or rigid, inclusion subject to both simple and pure shear boundary conditions. In these tests, we quantitatively compared our numerical results to analytical solutions. Then, we describe a model setup that can be used to understand field observations such as crystal orientation in dykes. Finally, we show that crystal-melt segregation is actually a viable mechanism during granitic magma ascent. In this 
paper, we present examples where all of the crystals introduced possess identical material properties and geometry.

\section{Numerical model}

In order to study the dynamics of a crystal suspension in an ascending magmatic flow, we define the system to be composed of highly viscous fluids. The equations governing creeping flow in two-dimensions are given by the Stokes equations (Eqs. 1-2) subject to the incompressibility constraint (Eq. 3):

$$
\begin{aligned}
& -\frac{\partial P}{\partial x}+\frac{\partial \tau_{x x}}{\partial x}+\frac{\partial \tau_{x z}}{\partial z}=0 \\
& -\frac{\partial P}{\partial z}+\frac{\partial \tau_{z z}}{\partial z}+\frac{\partial \tau_{z x}}{\partial x}=\rho g \\
& \frac{\partial V x}{\partial x}+\frac{\partial V z}{\partial z}=0
\end{aligned}
$$

where $P, \tau_{i j}, \rho$ and $g$ correspond to the pressure, the deviatoric stress tensor, the density, and the gravitational acceleration, respectively. $V x, V z$ are the two components of the velocity vector in $2 \mathrm{D}(x, z)$ Cartesian coordinate system.

We consider both the crystals and the melt as a linear viscous material. Their constitutive relationship is expressed as follows:

$$
\tau_{i j}=2 \eta \dot{\varepsilon}_{i j}
$$

where $\eta$ is the shear viscosity and $\dot{\varepsilon}_{i j}$ is the strain rate tensor defined as:

$$
\dot{\varepsilon}_{i j}=\frac{1}{2}\left(V_{i, j}+V_{j, i}\right)
$$


We approximate the crystals as an infinitely rigid material by prescribing a viscosity which is large compared to the viscosity of the surrounding fluid. This ensures that the strain rate inside the crystal is approximately zero. Thus, the crystal "rigidity" is defined by the viscosity ratio between the crystal and melt.

The use of Stokes flow to describe the evolution of the crystal-melt system is only valid if the flow in the dyke is laminar (i.e. Reynolds number lower than 1). The Reynolds number is given by:

$$
\operatorname{Re}=\frac{\rho_{\text {melt }} \cdot V \cdot W}{\eta_{\text {melt }}}
$$

where $\rho_{\text {melt }}, \eta_{\text {melt }}, V$ and $W$ are respectively the density of the melt, the viscosity of the melt, the flow velocity and the width of the channel. As the presence of crystals leads to a significant decrease of the velocity in the dyke, the highest value of the Reynolds number $R e$ is obtained for a dyke comprised only of melt (i.e., without crystals). For a melt density of $2400 \mathrm{~kg} . \mathrm{m}^{-3}$ and a large range of acceptable velocities (lower than $0.1 \mathrm{~m} . \mathrm{s}^{-1}$ ) and viscosities (higher than $10^{4}$ Pa.s), the value of $R e$ does not exceed $\sim 0.0125$ for a $0.5 \mathrm{~m}$ wide dyke. Consequently, viscous forces dominate the inertial forces, thereby justifying the use of Stokes equations to model crystal-melt dynamics in dykes.

We solve the equations (1-3) numerically using a code which employs an Eulerian staggered grid finite difference, particle-in-cell method (Gerya and Yuen, 2003; 2007).

The material properties, viscosity and density are defined on a set of Lagrangian particles that move through the model domain. To evaluate the finite difference stencil for the discrete stress tensor and the force term on the right hand side of equations (1-2) we interpolate the particle viscosity and density onto the finite difference grid. The interpolation used between 
the particles and the grid is described in section 3.1. Following the solution of equations (1-3) the particles are advected using a fourth-order accurate in space, first-order accurate in time, Runge-Kutta scheme. At each stage of the Runge-Kutta scheme, we define the velocity field at each marker position by interpolating the velocity field from the staggered grid using a bilinear function.

\section{Verification of the numerical scheme}

Before using our code to study flows with randomly distributed crystals, we performed several experiments involving a viscous inclusion for which we had an analytic solution for the velocity and pressure field. These tests were conducted in order to understand the discretisation errors associated with the method, and to verify that these discretisation errors decreased at the appropriate rate as the numerical resolution in the model was increased. In the crystal-free case, the flow induced by a pressure gradient is characterised by a Poiseuille-type flow. It was already shown that the shear component, particularly close to the edges of the dyke, causes pre-existing crystals to orient their major axis parallel to the flow direction (e.g., Petford and Koenders, 1998). Before examining the case of magmatic suspensions, it is important to verify that our numerical model is capable of correctly simulating both pure and simple shear regimes, and a Poiseuille flow.

\subsection{High viscosity inclusion in pure and simple shear regimes}

The first test verifies the accuracy of the velocity and the pressure fields for a model defining a circular inclusion of high viscosity, subject to a pure shear boundary condition (Schmid and Podladchikov, 2003). The viscosity ratio between the inclusion and the matrix has been set to 1000 (Fig. 1a) to allow direct comparison of the results with previous studies (e.g. Schmid and Podladchikov, 2003; Deublebeiss and Kaus, 2008). Zero density difference 
is prescribed between the inclusion and the matrix. In order to impose the strain rate boundary conditions similar to those used in Schmid and Podladchikov (2003), we evaluated the analytic velocity field at the boundary of the model domain, and used these values as Dirichlet boundary conditions. The initial setup and the results obtained for different numerical resolutions are shown on Fig. 1 (left panels). These results (Fig. 1b, left), which can also be compared with those of Deublebeiss and Kaus (2008), show that our numerical model provides a very close approximation of the analytical solution of Schmid and Podladchikov (2003).

We also considered an additional simple shear experiment (Fig. 1, right panels). As in the pure shear tests, we used a viscosity ratio of $10^{3}$ and constant density. The results from our model for the simple shear experiment (Fig. 1b, right) are again in good visual agreement with the analytic solution of Schmid and Podladchikov (2003). In both the pure and simple shear cases, we computed the difference between the numerical and analytical solution using an $L 1$ norm, where $L 1$ corresponds to a measure of the discretisation error (see Fig. 1c). The $L 1$ error for velocity and pressure is observed to decrease, with decreasing grid spacing $h$ (Fig. 1c). In these models, each cell is a square (same resolution in $x$ and $z$ directions). Fig. 1c displays a slope of $\sim 1$ in the $\log _{10}(L 1)$ vs. $\log _{10}(h)$ plot which means that the discretisation error decreases by a factor 2 when the grid spacing is divided by 2 .

In addition, we also performed several tests designed to evaluate two different interpolation schemes (i_mode, Fig. 1c), which are used to map the material properties (viscosity and density) from the markers to the grid. The interpolation mode corresponds to how the viscosity and the density values are interpolated from the particles to the cell vertices, and the cell centres (Fig. 2). The values of viscosity and density are required at these locations to define the finite difference stencil. An interpolation mode over 1 cell (denoted via i_mode $=1$-cell in Fig. 1c) corresponds to a distance weighted interpolation using all the particles 
included in a one cell area around the interpolation point, whereas a 4-cell interpolation (i_mode $=4$-cell in Fig. 1c) uses all particles contained in four cell areas for this operation (Fig. 2). The interpolation calculation is performed using the same method as described in Gerya and Yuen (2003). The only difference concerns the area of interpolation and thus, the number of particles taken into account. The main advantage of the 4-cell interpolation is that, for a given number of markers per cell, more markers are used for the interpolation calculation. However, the increase in the interpolation area can increase the error of the interpolated field (see discussion in section 3.2 and Fig. 3b). Concerning our test of a highly viscous inclusion in pure and simple shear regimes, the convergence rates obtained using 1cell or 4-cell averaging are very similar, however the pressure field obtained using the 4-cell average is less noisy (Fig. 1c).

\subsection{Rigid ellipse in a simple shear regime}

The first series of tests verified that the finite difference, particle-in-cell method produces convergent velocity and pressure fields for systems containing a stationary, circular viscous inclusion. In nature, crystals are non-circular and would rotate in a simple shear flow. Here, we consider several tests designed to verify that our code correctly models systems with these characteristics. Jeffery (1922) developed analytical solutions predicting the 3D trajectory and the angular velocity of a rigid ellipsoidal particle, as a function of its aspect ratio and the applied background shear strain. However, no analytical solution exists for the motion of a $2 \mathrm{D}$ rectangular body in a simple shear regime. In order to verify our numerical code, we decided to use the solution derived from the study by Jeffery (1922) and already used several times (e.g., Ghosh and Ramberg, 1976; Feng and Joseph 1995). We regard this solution appropriate for the purpose of code verification, as the geometry of the inclusion is an approximation of the rectangular crystal geometry we wish to model. This second test 
allowed us to check if the rotation rates computed numerically are correct and to choose a viscosity ratio between the crystal and melt which ensures that the crystal behaves as a rigid body. The rotation rate for the elliptical inclusion is given by:

$$
\dot{\chi}=\frac{\kappa}{a^{2}+b^{2}}\left(a^{2} \cos ^{2} \chi+b^{2} \sin ^{2} \chi\right)
$$

with,

$$
\tan \chi=\frac{a}{b} \tan \frac{a b \kappa t}{a^{2}+b^{2}}
$$

where $\dot{\chi}, a, b, \kappa$ and $t$ are the rotation rate, the half-length of the major axis, the half-length of the minor axis, the shear rate and the time, respectively. The same model setup as in Feng and Joseph (1995) is used and presented in Fig. 3a. The viscosity ratio between the clast (considered as a rigid ellipse) and the matrix is set to $10^{6}$ to mimic a rigid body.

The two interpolation modes were also tested here (Fig. 3b). In comparison with the analytic solution (solid red line), 4-cell interpolation is observed to be less accurate than the 1cell interpolation. We observe that the interpolation over 4 cells leads to an overestimated rotation rate. This can be explained by the fact that a larger interpolation area decreases the accuracy of the interpolation. The high viscosity at the edge of the ellipse is then computed with an effective viscosity ratio lower than the imposed one. As a consequence, in the following models of asymmetric rigid bodies, we have thus preferred an interpolation mode over 1 cell. Given that the numerical solution is in close agreement with the analytic solution, we can also conclude that our choice of viscosity ratio of $10^{6}$ between the crystal and melt is sufficient to approximate rigid bodies.

According to Jeffery's theory (1922), the rotation rate is higher when the ellipse is perpendicular to the shear direction and slower when the major axis of the ellipse is parallel to the shear (Fig. 3c and 3d). The fact that the rotation rate is much lower when the ellipse is parallel to the shear flow, compared to when it is perpendicular, leads on average over one 
period of revolution, to a preferential orientation of the major axis of the ellipse along the shear flow direction.

\subsection{Rigid ellipse in a Poiseuille flow}

Direct comparison of our numerical results with the analytical solution given by Feng and Joseph (1995) for a Poiseuille flow configuration is not possible because these authors included the inertia of both the ellipse and the fluid in their formulation. Since we are interested in studying low Reynolds numbers flows, we compared our results with those of Sugihara-Seki (1993) who performed similar experiments to Feng and Jospeh (1995) but without inertia, using a 2D finite element code (Fig. 4). The results we obtained for the longitudinal velocity of a neutrally buoyant elliptical cylinder (measured at the centreline) in a Poiseuille flow are in good visual agreement with the results of Sugihara-Seki (1993; his Table 1). The differences in non-dimensional velocities computed with the Sugihara-Seki (1993) solutions are always lower than $10^{-3}$ for resolutions higher than $201 \times 41$ nodes. This Poiseuille flow setup constitutes a supplementary test for the pressure computation in our code. Visually we obtain a similar pressure field to that of Sugihara-Seki, thus providing further confirmation of the accuracy of our pressure solution (Fig. 4b).

All these tests indicate that our code gives a good approximation of solutions for problems of rigid bodies in pure shear, simple shear and in Poiseuille flow conditions. It can now be used in more complex cases such as the simulation of magma transport in dykes involving "rigid" crystals suspended in a Newtonian melt. Following these results, for the remainder of this paper, a viscosity ratio of $10^{6}$ and the 1-cell averaging scheme are used for all calculations.

\section{Application to magma transport in dykes}




\subsection{Model setup}

Our model setup is constructed in a manner to produce an effective pressure gradient between the base and the top of a channel (simulating the dyke), by using a rigid piston pushed in a fluid perforated by a hole (Fig. 5). The fluid corresponds to the melt phase of the magmatic material that can be filled with crystals. The term magmatic, as in a mineralogical point of view, means a mixture composed of both melt and crystals (as in Fig. 5). The two main advantages of such a model are (1) that a large volume of crystal mush can easily be used to supply the dyke since the reservoir is included in the model domain and (2) that the mass balance is respected and that the effective background fluid pressure gradient $\left(P_{\text {driv }}\right)$ over the depth of the channel can be controlled by the velocity imposed at the edges of the two rigid blocks. In this way, no internal kinematic constraints are required within the model in order to drive the magmatic fluid.

In all the simulations we present here, we used a regular grid containing $401 \times 1551$ nodes, the interpolation between particles and nodes were carried out over 1 cell area (i_mode = 1-cell). Length units are fixed at $1 \mathrm{~m}, 0.5 \mathrm{~m}, 7.75 \mathrm{~m}$ and $5 \mathrm{~m}$ for $W, W_{d}, L$ and $L_{d}$, respectively (Fig. 5). In such a configuration, the resolution (i.e. the grid spacing) is thus 2.5 $\mathrm{mm}$ and $5 \mathrm{~mm}$ in the $x$ and $z$ direction, respectively. The size of each crystal is chosen to be $2.5 \times 7.5 \mathrm{~cm}$ in order to always ensure that each crystal is sufficient well resolved throughout the simulation. Such crystal sizes are quite large but not uncommon in granitic magma (Vernon and Paterson, 2008a; 2008b). However, since our flow is in a Stokes regime and we use a linear rheology, the principle of dynamic similarity can be applied. This implies that the dynamics is independent of the scale. For example, dividing all lengths scales in the model by a factor of two will lead to identical flow patterns, but the velocity field will be two times larger. Moreover, since this study is not focused on the influence of the crystal size, but rather on the influence of their presence in the melt, we consider this size suitable. The amount of 
crystals in the reservoir is set to $20 \%$ (Fig. 5). We first performed several resolution tests to confirm that the grid size used is appropriate to resolve the features of the crystalline flow (Fig. 6). Whilst the location and orientation of a particular crystal may slightly differ between the four panels in Fig 6, the global evolution of the crystals remain consistent with one another and show excellent visual agreement. We chose a relatively high grid resolution in order to avoid any artificial crystal clustering, which can occur if a too low numerical resolution is used. However, this resolution test shows that, in the future, simulations with a smaller crystal size could be run using the same grid resolution.

The viscosity of the melt and the crystals are chosen to be $10^{4} \mathrm{~Pa} . \mathrm{s}$ and $10^{10} \mathrm{~Pa} . \mathrm{s}$, corresponding to a viscosity ratio of $10^{6}$. This ratio is used to simulate crystals as rigid bodies. The densities used in the models are $2400 \mathrm{~kg} \cdot \mathrm{m}^{-3}$ and $2700 \mathrm{~kg} \cdot \mathrm{m}^{-3}$ for the melt and the crystals, respectively. For the rigid blocks, a viscosity of $10^{11} \mathrm{~Pa} . \mathrm{s}$ was chosen, and in order to avoid any influence between the block and the imposed velocity, the density of the block was chosen to be equal to that of the melt. Hence, no negative or positive buoyancy forces due to a density difference can perturb the vertical velocity we want to impose via these rigid blocks which act as pistons. Four cases are presented here, in which we tested the driving pressure gradient parameter $\left(P_{\text {driv }}\right)$ imposed through the dyke. This driving pressure gradient controls the magma ascent, and depends on the velocity of the lateral falling blocks (Fig. 5). In a pure melt dyke, the driving pressure gradient is such as:

$$
P_{d r i v}=-\frac{24 \cdot \eta_{m} \cdot V z_{b l o c k}}{W_{d}^{2}}
$$

where $\eta_{\mathrm{m}}, \mathrm{Vz}_{\text {block }}$ and $\mathrm{W}_{d}$ correspond to the viscosity of the magma, the velocity of the lateral falling blocks and the dyke width, respectively (see appendix A). Indeed, imposing the sinking velocity of the rigid blocks corresponds to a pressure gradient. When the applied velocity is zero (experiment $V z=0$ ), the only force acting on the magma is its buoyancy. As a result, when considering pure melt and $V z=0$, the pressure gradient is equal to $24000 \mathrm{~Pa}^{-1} \mathrm{~m}^{-1}$ 
$\left(\rho_{\text {melt }} . g=2400 \times 10=24000\right)$. This value corresponds to the force needed to compensate the weight of the melt column, ensured by the free-slip boundary condition at the bottom, which prevents the material from leaving the model domain. In order to move the magma upward, the applied pressure gradient must be higher than this buoyancy value, i.e. the system below the piston needs to be over-pressured. In the three cases presented below, this pressure gradient is ensured by using imposed velocities at the edges of the blocks of $5.10^{-2} \mathrm{~m} \cdot \mathrm{s}^{-1}$ (experiment High $V z$ ), $1.10^{-4} \mathrm{~m} . \mathrm{s}^{-1}$ (experiment Intermediate $V z$ ) and $5.10^{-5} \mathrm{~m} . \mathrm{s}^{-1}$ (experiment Low $V z$ ). Using the equation (Eq. 9) and assuming a $50 \mathrm{~cm}$ width dyke, we thus obtain realistic absolute driving pressure gradient values for $P_{\text {driv }}$ of 48000, 96 and $48 \mathrm{~Pa}^{-1}$, respectively (e.g., Wilson and Head, 1988).

\subsection{Effect of crystalline load on the dyke's flow profile}

The presence of crystals in an ascending magma alters the vertical velocity profile across the width of the dyke. In the crystal-free simulations, the fit between the computed vertical velocity and the analytical solution is very good (Fig. 7a). This velocity profile is typical of that expected in a Poiseuille flow. The Fig. $7 \mathrm{~b}$ shows that the presence of crystals radically alters the parabolic shape of the vertical velocity profile. Low vertical velocities characterise regions where crystals are concentrated. On the other hand, crystal-free areas are preferential corridors in which the melt quickly ascends. This is illustrated in Fig. 7c where several vertical velocity profiles from different heights in the dyke are shown. Vertical velocity profiles computed at $Z=-5 \mathrm{~m}$ and $Z=-5.5 \mathrm{~m}$ are similar, displaying both high and low velocity zones. An interesting feature is that vertical velocities are the highest along the dyke margins, and this value can be larger than the maximum theoretical velocity calculated in the crystal-free case. This illustrates the mechanism of lubrication along the conduit margins already highlighted by Nkono et al. (2006). The integrated velocity profiles over 2 
meters (green curve in Fig. 7c) shows a roughly defined flat plateau. The irregular shape of this plateau is attributed to the large size of the crystals. Decreasing the size of the crystals (and thus increasing the number of crystals required to maintain the same percentage by volume) would necessarily smooth this plateau. This plateau shape is typical of a Bingham flow, which is representative of crystal-bearing magmatic flows (e.g. Walsh and Saar, 2008).

\subsection{Crystal displacement toward the centre of the dyke}

Analogue experiments conducted by Bhattacharji (1967) have shown that magma flow provokes an accumulation of the pre-existing solid particles toward the centre of the dyke, due to the Bagnold effect (Bagnold, 1954), even at relatively low crystal content of ca. 15 vol.\%. Analytical calculations have confirmed this phenomenon, showing that a hydrodynamic grain dispersive pressure regroups phenocrysts in the centre of the dyke, provided that their volume concentration reaches ca. 8\% (Komar, 1972). The size of the phenocrysts is an important parameter in this process; the larger their size, the more efficient the sorting is (Komar, 1972; Barrière, 1976). In our numerical experiments, we do not observe this phenomenon. This could be due to the fact that all the crystals in the numerical experiments have the same size and shape. Indeed, as mentioned above, crystal size is a major parameter controlling this process. Additional experiments utilising various crystal sizes, shapes and distributions of crystal sizes are needed to understand the absence of the Bagnold effect in our numerical models.

\subsection{Crystal rotation during magma flow}

We demonstrated above that the numerical code we have developed is capable of modelling the rotation rates of a rigid inclusion immersed in a viscous liquid undergoing simple shear. In a Poiseuille flow, the velocity field is parabolic and represents a simple shear 
component that increases linearly from the centre to the edge. Suspended crystals carried by the melt phase continually rotate during magma ascent. Crystals located in the left part of the dyke rotate counter-clockwise while, in contrast, crystals located in the right part of the dyke rotate clockwise. As mentioned in the section 3.2 and according to Jeffery's theory (1922), advected crystals are continuously rotating. Therefore, no specific crystal orientations should be stable. However, for the crystal aspect ratio employed, the rotation rate is about 3 times larger when the major axis is perpendicular to the flow (i.e. the $z$-axis or the wall plane) and slower when the major axis of the ellipse is parallel to the flow. For each crystal, this variation of rotation rate that occurs over one period of revolution explains why crystals are more often found orientated parallel or at a very low angle to the flow direction rather than perpendicular to it. This is illustrated in Fig. 8. Histograms of the crystal orientation in the dyke show that the more the magma ascends, the more the statistical orientation of the crystals tends to be parallel to the flow direction. This may explain why field observations of dyke textures usually show aligned crystals in the flow direction (e.g. Smith, 2002; Paterson, 2009). The observed statistical orientation of the crystals is also in good agreement with the anisotropy of magnetic susceptibility (AMS) studies that show that the statistical alignment of the major axes of phenocrysts (magnetic lineation $\mathrm{K} 1$ ) is parallel or at low angle to the flow direction (e.g., Ildefonse et al., 1992; Arbaret et al., 1996; Geoffroy et al., 2002). In addition, the fact that crystals located to the right of the dyke centre rotate clockwise and those located to the left of the dyke centre rotate counter clockwise leads to the tilling of the crystals (see Fig. 8 at $\mathrm{t}=20 \mathrm{~s}$, or Fig. 9, High $V z$ experiment) with a superposition angle in agreement with the sense of the magma flow as determined from AMS studies (e.g., Knight and Walker, 1988, Varga et al., 1998, Geoffroy et al., 2002).

\subsection{Crystal-melt segregation and magmatic differentiation}


Based on petrographical observations and geochemical data, Tartèse and Boulvais (2010) proposed a mechanism of magmatic differentiation "en route" to the surface. With this mechanism, suspended crystals are segregated from the carrying melt phase at depth during magma ascent in dykes. As a result of this process, the larger the vertical distance the ascending magma has travelled, the more differentiated the resulting magma becomes. The main controls on this process of crystal-melt fractionation are physical factors like melt viscosity, crystal size or the density difference between the melt and the crystals. If crystal fractionation from the melt in mafic magmas is well accepted as a mechanism of differentiation (e.g., Philpotts et al., 1998), such a process is usually considered as unlikely in granitic magmas because of the belief that they are too viscous, and that the density difference between the melt and the crystals is not sufficient.

In the simulations presented in Fig. 9, the melt phase can effectively be squeezed out from the crystalline network. The primary control on this mechanism is the pressure gradient applied on the magma. On one hand, if the pressure gradient is low, the magma cannot rise into the dyke and the crystals fall to the base of the tank $(V z=0$ experiment in Fig. 9, bottom). Conversely, when the applied pressure gradient is large, the magma rises very quickly, preventing any crystal-melt segregation to occur (High Vz experiment in Fig. 9). In the simulations presented Fig. 9, the melt phase is segregated from the crystal-rich mush in the Low $V z$ and Intermediate $V z$ experiments, which corresponds to a driving pressure gradient of 48 and 96 Pa.m ${ }^{-1}$, respectively.

\section{Conclusion and perspectives}

In this study we have presented a numerical technique to model magmatic flows within a dyke. The main results can be summarized as follow: 
(1) Our code has been verified against several analytical solutions that possess characteristics similar to those found in crystal-melt systems. These tests indicate that the marker to node interpolation using 1-cell area is more accurate for problems that include rotating, noncircular rigid-bodies.

(2) The simulations presented here clearly illustrate that crystals rotate continually in an ascending magma, and why field observations of frozen dykes typically display crystals with their major axis usually orientated parallel to the flow direction.

(3) The presence of crystals modifies the velocity profile from a typical parabolic shape (Poiseuille flow) to a Bingham-type shape. Thus, despite the usage of a linear rheology, the presence of rigid crystals introduces an effective bulk non-Newtonian behaviour.

(4) The segregation of granitic melt from an ascending crystal-rich magma is physically possible for the classical values of viscosity $\left(10^{4} \mathrm{~Pa} . \mathrm{s}\right)$ and density of granitic material (2400 and $2700 \mathrm{~kg} \cdot \mathrm{m}^{-3}$ for the melt and the crystals, respectively).

The numerical modelling technique developed here can be readily applied to many different types of crystal-melt studies. In particular, it would be straightforward to apply this type of model to evaluate the effective viscosity of magmas with different types of crystalline loads (various crystal sizes and shapes), and to examine the influence of dyke morphology in conjunction with various crystal sizes. 


\section{Appendix A: Maximum velocity in dyke and driving pressure gradient calculation}

The advantage of our setup is that it provides a way to control the effective pressure gradient (and thus, the maximum vertical velocity) in the dyke via the imposed velocity of the lateral blocks (see Fig. 5). In the case of a pure melt dyke (see Fig. A1), we can derive an expression which relates the applied velocity of the rigid blocks $V z_{\text {block }}$, to the driving pressure gradient $P_{\text {driv }}$ :

Over one time step $(d t)$, the area of the block buried in the fluid $\left(\mathrm{A}_{\text {block }}\right)$ is:

$$
\mathrm{A}_{\text {block }}=W_{b} \cdot V z_{\text {block }} \cdot d t
$$

where $W_{b}$ and $V z_{\text {block }}$ correspond, respectively, to the width of the rigid block and to the imposed velocity (Fig. A1). In the same time, melt is expulsed in the dyke following a quadratic Poiseuille flow. In 2D, the amount of melt expulsed corresponds to the area located below the parabola describing this flow ( $\mathrm{A}_{\text {parab }}$, see Fig. $\left.\mathrm{A} 1\right)$. The area under the parabola $\left(A_{\text {parab }}\right)$ is given by

$$
\mathrm{A}_{\text {parab }}=\frac{2}{3} \cdot W_{d} \cdot V z_{\max } \cdot d t
$$

where $W_{d}$ and $V z_{\max }$ are, respectively, the width of the dyke and the maximum vertical velocity of the Poiseuille flow (Fig. A1). Since the fluid we consider is incompressible, mass flow across horizontal interfaces defining the bottom of the blocks must be conserved. That is, we require that

$$
2 \mathrm{~A}_{\text {block }}=\mathrm{A}_{\text {parab }}
$$

noting that the factor two comes from the fact that we have a block on each side of the dyke. In this study, the rigid block width $\left(W_{b}\right)$ is always two times thinner than the dyke width $\left(W_{d}\right)$, i.e. $W_{d}=2 W_{b}$. Equating equations (A.1) and (A.2) and using the mass conservation condition in (A.3), we obtain the following expression for the maximum vertical velocity of the flow $\left(V z_{\max }\right)$ as a function of the velocity imposed to each rigid block $\left(V z_{\text {block }}\right)$ : 


$$
V z_{\max }=3 \cdot V z_{\text {block }}
$$

The vertical velocity profile equation in a Poiseuille flow is given by:

$$
V z(x)=-\frac{1}{2 \eta_{m}}\left(\rho_{m} g+\frac{d P}{d z}\right)\left(x W_{d}-x^{2}\right)
$$

where $\eta_{m}, \rho_{m}, \mathrm{~g}$ and $\frac{d P}{d z}$ are the viscosity of the melt, the density of the melt, the gravitational acceleration and the total pressure gradient through the dyke.

Using equation (A.5), in the middle of the dyke (i.e., at $\mathrm{x}=0.5 W_{d}$ ), where the vertical velocity is maximum $\left(V z_{\max }\right)$, we can write:

$$
V z_{\max }=-\frac{1}{8 \eta_{m}} \cdot P_{d r i v} \cdot W_{d}^{2}
$$

where $P_{\text {driv }}$ corresponds to the driving pressure gradient resulting from both the melt weight and the pressure gradient induced by the rigid lateral blocks such as:

$$
P_{d r i v}=\rho_{m} g+\frac{d P}{d z}
$$

The driving pressure gradient can thus be expressed in function of the imposed velocity on the rigid block combining the equations (A.4) and (A.6):

$$
P_{d r i v}=-\frac{24 \cdot \eta_{m} \cdot V z_{\text {block }}}{W_{d}^{2}}
$$

In addition, these values of $V z_{\max }$ and $P_{\text {driv }}$ have also been calculated numerically in our simulations and give the same results.

\section{Acknowledgments}

We first thank F.O. Marques and the GeoMod2010 team for the workshop organization where multiple discussions and debates have initiated this work. Discussions with B. Kaus and M. Dabrowski were greatly appreciated. A special “спасибо” is addressed to T. Gerya for his constant support and enthusiasm during coding using the M-I-C method. 
Multiple stimulating discussions with E. Hallot, K. Gallagher, P. Boulvais, M. Poujol, W. Husson and B. Cordonnier were also appreciated. Finally, we also thank D. Schmid and an anonymous reviewer for their constructive reviews that have substantially improved the manuscript. Author DAM was financially supported by the ETH Zurich Postdoctoral Fellowship Program. High-resolution simulations were performed on the ETH brutus cluster.

\section{References}

Arbaret, L., Diot, H., Bouchez, J.L, 1996. Shape fabrics of particles in low concentration suspensions: 2D analogue experiments and application to tiling in magma. J. Struct. Geol. 18, 941-950.

Arbaret, L., Mancktelow, N.S., Burg, J.P., 2001. Effect of shape and orientation on rigid particle rotation and matrix deformation in simple shear flow. J. Struct. Geol. 23, 113-125.

Bagdassarov, N., Dorfman, A., 1998. Granite rheology: magma flow and melt migration. J. Geol. Soc. 155, 863-872.

Bagnold, R.A, 1954. Experiments on a gravity-free dispersion of large solid spheres in a Newtonian fluid under shear. Roy. Soc. London Proc. 225, 49-63.

Barrière, M., 1976. Flowage differentiation: limitation of the "Bagnold effect" to the narrow intrusions. Contrib. Mineral. Petr. 55, 139-145.

Bhattacharji, S., 1967. Mechanics of flow differentiation in ultramafic and mafic sills. J. Geol. 75, 101-111.

Bons, P.D., Barr, T.D., ten Brink, C.E., 1996. The development of $\delta$-clasts in nonlinear viscous materials: a numerical approach. Tectonophysics 270, 29-41

Caricchi, L., Burlini, L., Ulmer, P., Gerya, T., Vassalli, M., Papale, P., 2007. NonNewtonian rheology of crystal-bearing magmas and implications for magma ascent dynamics. Earth Planet. Sc. Lett. 264, 402-419. 
Champallier, R., Bystricky, M., Arbaret, L., 2008. Experimental investigation of magma rheology at $300 \mathrm{MPa}$ : From pure hydrous melt to 76 vol.\% of crystals. Earth Planet. Sc. Lett. $267,571-583$.

Chistyakova, S., Latypov, R., 2010. On the development of internal chemical zonations in small mafic dykes. Geol. Mag. 147, 1-12.

Clemens, J.D., 1998. Observations on the origins and ascent mechanisms of granitic magmas. J. Geol. Soc. 155, 843-851.

Clemens, J.D., 2003. S-type granitic magmas-petrogenetic issues, models and evidence. Earth Sci. Rev. 61, 1-18.

Clemens, J.D., Mawer, C.K., 1992. Granitic magma transport by fracture propagation: Tectonophysics 204, 339-360.

Clemens, J.D., Petford, N., 1999. Granitic melt viscosity and silicic magma dynamics in contrasting tectonic settings. J. Geol. Soc. 156, 1057-1060.

Costa, A., Melnik, O., Sparks, R.S.J., Voight, B., 2007. Control of magma flow in dykes on cyclic lava dome extrusion. Geophys. Res. Lett. 34, L02303.

Deublebeiss, Y., Kaus, B.J.P., 2008. Comparison of Eulerian and Lagrangian numerical techniques for the Stokes equations in the presence of strongly varying viscosity. Phys. Earth Planet. In. 171, 92-111.

Deublebeiss, Y., Kaus, B.J.P., Connolly, J.A.D., 2010. Direct numerical simulation of two-phase flow: Effective rheology and flow patterns of particle suspensions. Earth Planet. Sc. Lett. 290, 1-12.

Dingwell, D.B., 1996. Volcanic dilemma: flow or blow? Science 273, 1054-1055.

Einstein, A., 1906. Eine neue Bestimmung der Moleküldimensionen. Ann. Phys. 19, 289-306. 
Feng, J., Joseph, D.D., 1995. The unsteady motion of solid bodies in creeping flows. J. Fluid Mech. 303, 83-102.

Geoffroy, L., Callot, J.P., Aubourg, C., Moreira, M., 2002. Magnetic and plagioclase linear fabric discrepancy in dykes: a new way to define the flow vector using magnetic foliation. Terra Nova 14, 183-190.

Gerya, T.V., Yuen, D., 2003. Characteristics-based marker-in-cell method with conservative finite-differences schemes for modeling geological flows with strongly variable transport properties. Phys. Earth Planet. In. 140, 293-318.

Gerya, T.V., Yuen, D., 2007. Robust characteristics method for modelling multiphase visco-elasto-plastic thermo-mechanical problems. Phys. Earth Planet. In. 163, 83-105.

Ghosh, S.K., Ramberg, H., 1976. Reorientation of inclusions by combination of pure shear and simple shear. Tectonophysics 34, 1-70.

Hallot, E., Davy, P., de Bremond d'Ars, J., Auvray, B., Martin, H., Van Damme, H., 1996. Non-Newtonian effects during injection in partially crystallised magmas. J. Volcanol. Geotherm. Res. 71, 31-44.

Ildefonse, B., Launeau, P., Bouchez, J.L., Fernandez, A., 1992. Effect of mechanical interactions on the development of shape preferred orientation: a two-dimensional experimental approach. J. Struct. Geol. 14, 73-83.

Jeffery, G., 1922. The motion of ellipsoidal particles immersed in a viscous fluid. Proc. Roy. Soc. London A102, 201-211.

Kerr, R.C., Lister, J.R., 1991. The effects of shape on crystal settling and on the rheology of magmas. J. Geol. 99, 457-467.

Knight, M.D., Walker, G.P.L., 1988. Magma flow direction in dykes of the Koolau complex, Oahu, determined from magnetic fabric studies. J. Geophys. Res. 93, 4301-4319. 
Komar, P.D., 1972a. Mechanical interactions of phenocrysts and flow differentiation of igneous dykes and sills. Geol. Soc. Am. Bull. 83, 973-988.

Komar, P.D., 1972b. Flow differentiation in igneous dikes and sills: Profiles of velocity and phenocryst concentration. Geol. Soc. Am. Bull. 83, 3443-3448.

Mandal, N., Samanta, S.K., Chakraborty, C., 2001. Numerical modeling of heterogeneous flow fields around rigid objects with special reference to particle paths, strain shadows and foliation drag. Tectonophysics 330, 177-194.

Marques, F.O., Burlini, L., 2008. Rigid inclusions rotate in geologic materials as shown by torsion experiments. J. Struct. Geol. 30, 1368-1371.

Marques, F.O., Coelho, S., 2001. Rotation of rigid elliptical cylinders in viscous simple shear flow: analogue experiments. J. Struct. Geol. 23, 609-617.

Marques, F.O., Coelho, S., 2003. 2-D shape preferred orientations of rigid particles in transtensional viscous flow. J. Struct. Geol. 25, 841-854.

Marques, F.O., Taborda, R., Antunes, J., 2005a. Influence of a low-viscosity layer between rigid inclusion and viscous matrix on inclusion rotation and matrix flow: A numerical study. Tectonophysics 407, 101-115.

Marques, F.O., Taborda, R.M., Antunes, J.V., 2005b. 2D rotation of rigid inclusions in confined bulk simple shear flow: a numerical study. J. Struct. Geol. 27, 2171-2180.

Melnik, O., Sparks, R.S.J., 1999. Nonlinear dynamics of lava dome extrusion. Nature $402,37-41$.

Nkono, C., Féménias, O., Diot, H., Berza, T., Demaiffe, D., 2006. Flowage differentiation in an andesitic dyke of the Motru Dyke Swarm (Southern Carpathians, Romania) inferred from AMS, CSD and geochemistry. J. Volcanol. Geoth. Res. 154, 201221. 
Papale, P., 1999. Strain-induced magma fragmentation in explosive eruptions. Nature $397,425-428$.

Paterson, S.R., 2009. Magmatic tubes, pipes, troughs, diapirs, and plumes: Late-stage convective instabilities resulting in compositional diversity and permeable networks in crystal-rich magmas of the Tuolumne batholith, Sierra Nevada, California. Geosphere 5, 496527.

Petford, N., 2003, Rheology of granitic magma during ascent and emplacement. Annu. Rev. Earth P1. Sc. 31, 399-427.

Petford, N, Lister, J.R., Kerr, R.C., 1994. The ascent of felsic magmas in dykes: Lithos $32,161-168$.

Petford, N., Koenders, M.A., 1998. Granular flow and viscous fluctuations in low Bagnold number granitic magmas. J. Geol. Soc. 155, 873-881.

Philpotts, A.R., Shi, J., Brustman, C., 1998. Role of plagioclase crystal chains in the differentiation of partly crystallized basaltic magma. Nature 395, 343-346.

Roscoe, R., 1953. Suspensions, in: Hermans, J.J. (Eds.), Flow Properties of Disperse Systems. North Holland, Amsterdam, pp. 1-38.

Samanta, S.K., Mandal, N., Chakraborty, C., 2002. Development of structures under the influence of heterogeneous flow field around rigid inclusions; insights from theoretical and numerical models. Earth Sci. Rev. 58, 85-119.

Scaillet, B., Holtz, F., Pichavant, M., 1998. Phase equilibrium constraints on the viscosity of silicic magmas. 1. Volcanic-plutonic comparison. J. Geophys. Res. 103, 2725727266.

Schmid, D.W., 2005. Rigid polygons in shear, in: Bruhn, D., Burlini, L. (Eds), High strain zones: structure and physical properties. Geol. Soc. London Spec. Pub. 245, pp. 421431. 
Schmid, D.W., Podladchikov, Y.Y., 2003. Analytical solutions for deformable elliptical inclusions in general shear. Geophys. J. Int. 155, 269-288.

Smith, J.V., 2002. Structural analysis of f low-related textures in lavas. Earth Sci. Rev. 57, 279-297.

Sugihara-Seki, M., 1993. The motion of an elliptical cylinder in channel flow at low Reynolds numbers. J. Fluid Mech. 257, 575-596.

Taisne, B., Jaupart, C., 2011. Magma expansion and fragmentation in a propagating dyke. Earth Planet. Sc. Lett. 301, 146-152.

Tartèse R., Boulvais P., 2010. Differentiation of peraluminous granites "en route" to the surface. Lithos 114, 353-358.

Varga, R.J., Gee, J.S., Staudigel, H., Tauxe, L., 1998. Dykes surface lineation as magma flow indicators within the sheeted dyke complex of the Troodos ophiolite, Cyprus. J. Geophys. Res. 103, 5241-5256.

Vernon, R.H., Paterson, S.R., 2008a. How late are K-feldspar megacrysts in granites? Lithos 104, 327-336.

Vernon, R.H., Paterson, S.R., 2008b. How extensive are subsolidus grain-shape changes in cooling granites? Lithos 105, 85-97.

Vigneresse J.L., Barbey P., Cuney M., 1996. Rheological transitions during partial melting and crystallisation with application to felsic magma segregation and transfer. J. Petrol. 37, 1579-1600.

Van den Driessche, J., Brun, J.P., 1987. Rolling structures at large shear strain. J. Struct. Geol. 9, 691-704.

Walsh, S.D.C., Saar, M.O., 2008. Numerical models of stiffness and yield stress growth in crystal-melt suspensions. Earth Planet. Sc. Lett. 267, 32-44. 
Willis, D.G., 1977. A kinematic model of preferred orientation. Geol. Soc. Am. Bull. $88,883-894$.

Wilson, L., Head, J.W., 1988. Nature of magma storage zones and geometry of conduit systems below basaltic eruption sites: Pu'u 'O'o, Kilauea East Rift, Hawaii example. J. Geophys. Res. 93 (B12), 14785-14792. 


\section{Figure Captions:}

Fig. 1. Comparison of numerical results with analytical solutions for a rigid circular inclusion in a pure shear (left) and simple shear (right) regime. a) Model setup (see text for details). b) Comparison of the computed 2D pressure field with the analytical solution. In this example, the resolution of the model is $280 \times 280$ grid points with 9 particles per cell c) Error between our results and the analytical solution $(L 1)$ vs. the cell size $(h)$ for two different interpolation modes (see text for details). The $L 1$ value corresponds to the sum of the difference between the numerical and the analytical value for the field $X$ at each point $i$ divided by the number of points considered $(N x) . X$ can thus be the pressure $(P)$, the $x$-component of the velocity vector $(V x)$, or the $z$-component of the velocity vector $(V z)$. Using a staggered grid, in a model with $n x$ nodes in the $x$ direction and $n y$ nodes in the $z$ direction, the value of $N x$ is $(n x-1) \times(n z-1)$, $n x \times(n z-1)$ and $(n x-1) \times n z$ for $P, V x$ and $V z$ respectively.

Fig. 2. Interpolation mode definitions. The different modes of interpolations are based on the size of the interpolation area. Here, we illustrate an example of interpolation from the particles, to the centre of the cell, for a case with 9 particles per cell. On the left, 1-cell interpolation mode: the weighted interpolation is performed using all the particles included in a 1-cell area around the interpolation point. The length of the square edge including the particles used is thus $h$, which corresponds to the size of the cell. On the right, 4-cell interpolation mode: the weighted interpolation is performed using all the particles included in a 4-cell area around the interpolation point.

Fig. 3. Comparison of the numerical results with the analytical solution for a rigid elliptical body in a simple shear flow. a) Model setup, identical to the one of Feng and Joseph (1995). Here, $U=10 \mathrm{~m} \cdot \mathrm{s}^{-1}$ and $H=1 \mathrm{~m} . a$ and $b$ correspond to the major and minor semi-axis of the 
elliptical inclusion, respectively. b) Variation of the angular velocity $\dot{\chi}$ vs. time obtained for different grid resolutions and interpolation modes (see text for details). c) Evolution of the ellipse through time. The two horizontal light grey layers in the matrix and the two dark grey regions in the ellipse have been added for visualisation only. d) Evolution of the rotation rate of the ellipse through time.

Fig. 4. Rigid ellipse in a Poiseuille flow. a) Model setup, similar to the one of Sugihara-Seki (1993); $H=1, a=0.4, b=0.2$ and $\theta=0.2 \pi$, the viscosity of the matrix $\mu_{\text {matrix }}$ is 1 and $U_{\max }$ is set to 10 (non-dimensional values) as in his experiment. b) Pressure field computed. As in Sugihara-Seki (1993), the colour scale denotes $\left(p-p_{m}\right) d / \mu U_{\max }$ where $p_{m}$ represents the average of the upstream $(x=0)$ and downstream $(x=W)$ pressures.

Fig. 5. Rigid piston setup (not shown to scale). The lengths $L, L_{d}, W$ and $W_{d}$ correspond to the length of the model, the length of the dyke, the width of the model and the width of the dyke, respectively. In our models $L \gg>$, thus for clarity only a portion of the model domain is shown (the wavy white line denotes the cut). The model is thus composed of two parts: A reservoir, filled with magma ( $80 \%$ of melt $+20 \%$ of crystals) at the bottom, and the dyke located above. $\eta_{c}, \rho_{c}, \eta_{m}$ and $\rho_{m}$ correspond to the viscosity and the density of the crystals and of the melt, respectively.

Fig. 6. Resolution tests performed for the High $V z$ experiment (see text for details of the setup). "res" corresponds to the grid resolution (number of nodes in the $x$ direction multiplied by the number of nodes in the $z$ direction). Both the light grey layering and red layering constitute the same material property (melt). They are added here to facilitate visualisation of the deformation field. Red melt corresponds to the melt originally located in the reservoir, 
which contains crystals. Grey melt denotes the melt already in the channel when the experiment starts. Crystals are plotted in black and the dark grey corresponds to the dyke walls (i.e., the rigid blocks). Results show a good visual agreement, even when using the lowest grid resolution.

Fig. 7. Real vertical velocity component within the dyke $\left(V z_{t o t}+V z_{\text {imposed }}\right)$. Indeed, in order to obtain a vertical velocity equal to zero at the dyke walls (i.e. fix walls), the velocities presented here correspond to the vertical velocity component computed (called $V z_{t o t}$ ) added to the vertical velocity imposed at the edges of the rigid block (called $V z_{\text {imposed }}$ ). a) Velocity profile computed in the middle of the dyke for all experiments without any crystal load. $V z_{\max }$ values are then $0.15 \mathrm{~m} \cdot \mathrm{s}^{-1}, 3.10^{-4} \mathrm{~m} \cdot \mathrm{s}^{-1}$ and $1.5 .10^{-4} \mathrm{~m} \cdot \mathrm{s}^{-1}$ for High $V z$, Intermediate $V z$ and Low $V z$ experiments, respectively. b) $V z$ plot in the dyke at $t \sim 6000 \mathrm{~s}$ for the Intermediate $V z$ experiment. Crystals are shown as black ghosts. c) In red, vertical velocity profile obtained in the crystal-free model under the same conditions as the Intermediate Vz experiment. The grey profiles correspond to 2 individual transects at $Z=-5 \mathrm{~m}$ (plain) and $Z=-5.5 \mathrm{~m}$ (dots). The green profile corresponds to an average of all the velocity profiles integrated between $Z=-$ $5.75 \mathrm{~m}$ and $Z=-4.75 \mathrm{~m}$.

Fig. 8. Crystal rotation during magma flow. Snapshots have been taken at 0,10 and $20 \mathrm{~s}$ in the High $V z$ experiment (upper part). The statistical orientation of the first 30 crystals entered in the dyke has been computed and is displayed as frequency histograms (lower part). The colours represent the same quantities defined in Fig. 6.

Fig. 9. Results of the experiments as a function of the applied driving pressure gradient $\left(P_{\text {driv }}\right)$. The colours represent the same quantities defined in Fig. 6 and 8. a) Initial configuration 
showing the location of the zoom regions presented in b. b) Evolution of the models through time (see text for detailed description).

Fig. A1. Schematic evolution of a model constituted by pure melt with a viscosity $\eta_{m}$ and a density $\rho_{m}$ between the time $t$ (left) and the time $t+d t$ (right). The imposed velocity $\left(V z_{\text {block }}\right)$ is applied at the edges of the rigid blocks as describes in our model setup. Since the volumes are conserved and considering a dyke width $\left(W_{d}\right)$ two times larger than a rigid body width $\left(W_{b}\right)$, the amount of melt entering in the dyke $\left(\mathrm{A}_{\text {parab }}\right)$ correspond to four times the amount of rigid block buried in depth $\left(\mathrm{A}_{\text {block }}\right)$. See Appendix A1 for more details. 
PURE SHEAR

a

\section{$V z_{\text {top }}$}

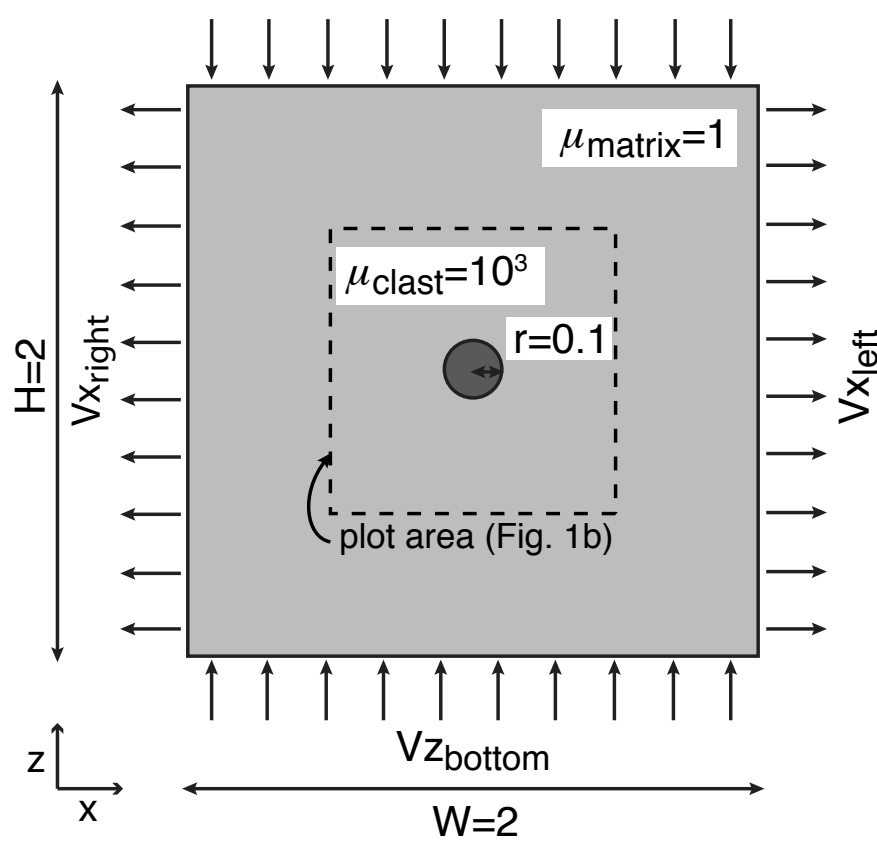

b

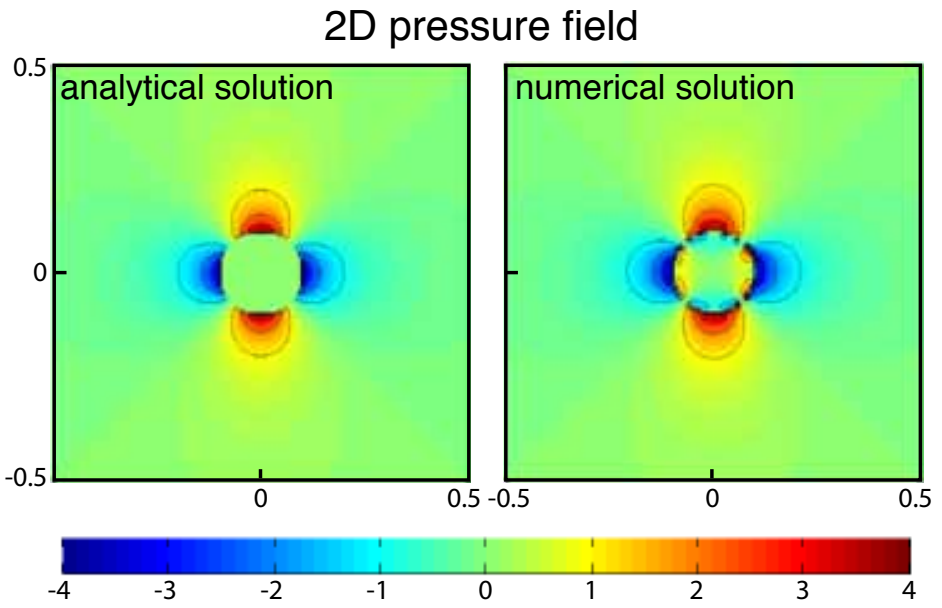

SIMPLE SHEAR

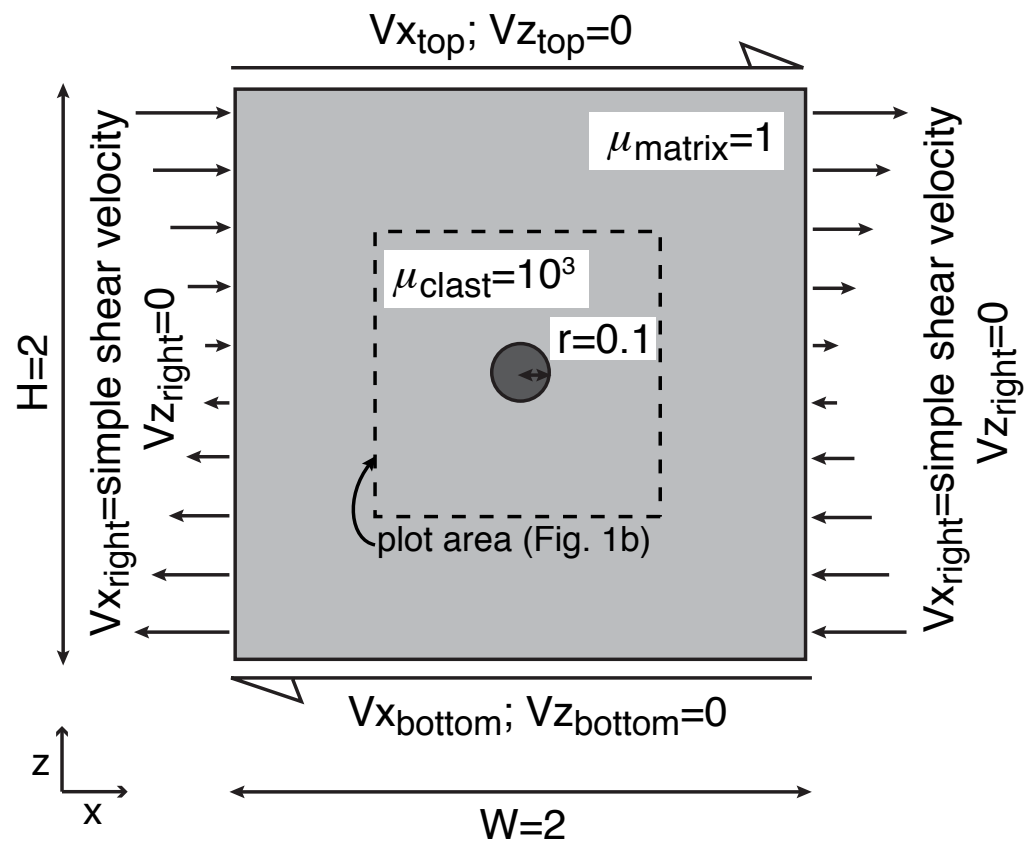

2D pressure field

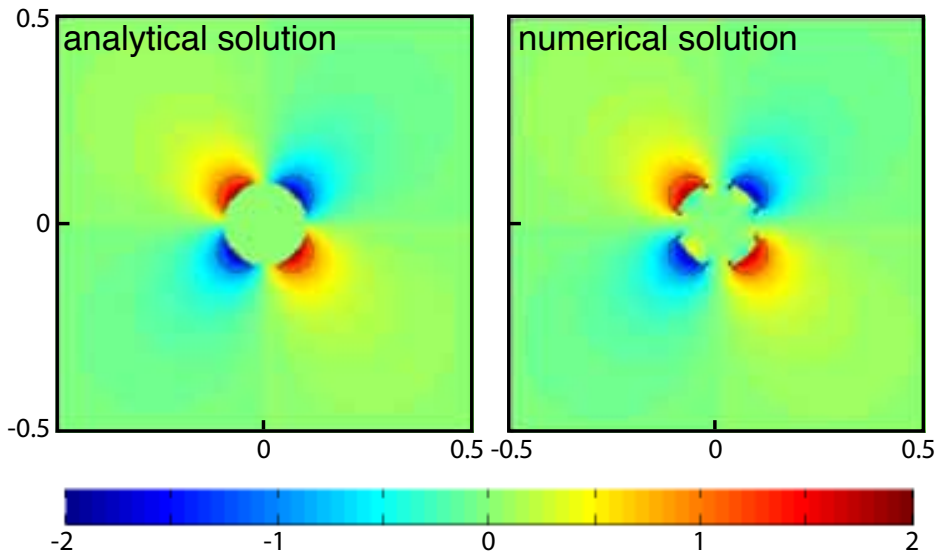

C

$$
\mathrm{L} 1=\frac{\sum_{i=1}^{n}\left\|\mathrm{X}_{i}^{\text {ana }}-\mathrm{X}_{i}^{\mathrm{num}}\right\|}{\mathrm{N}_{X}}
$$

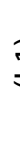

\begin{tabular}{l}
0 \\
\hline \\
0 \\
0
\end{tabular}

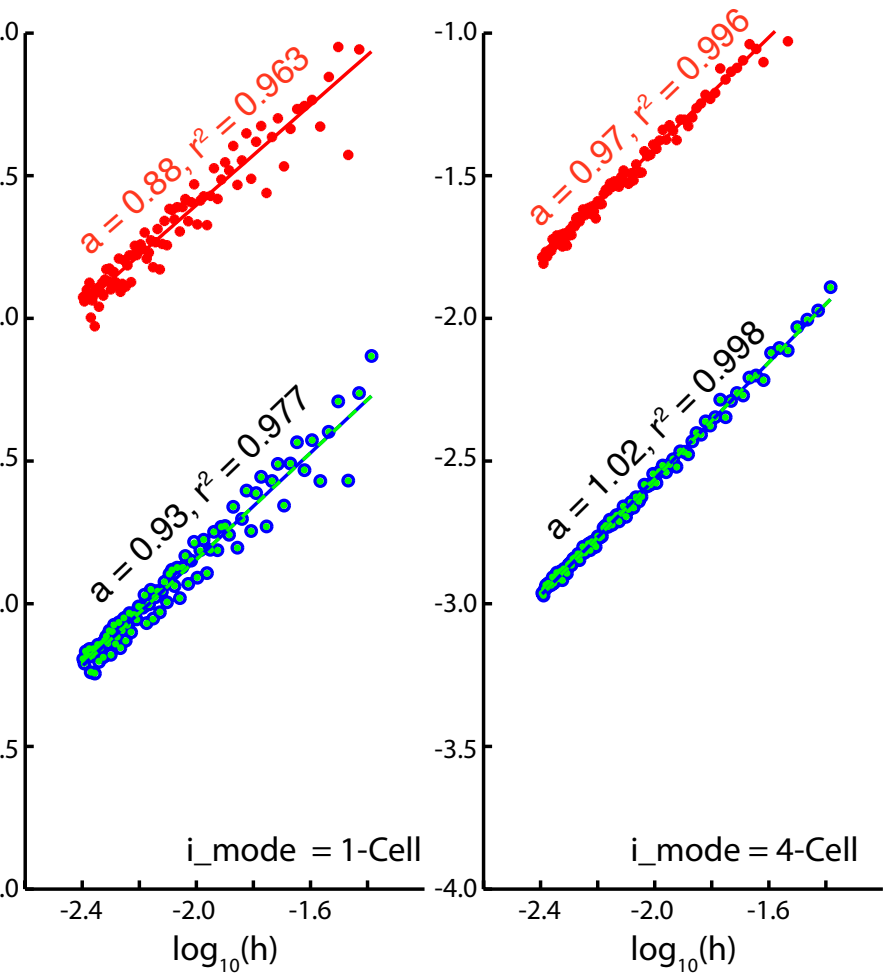

- pressure oVx • Vz

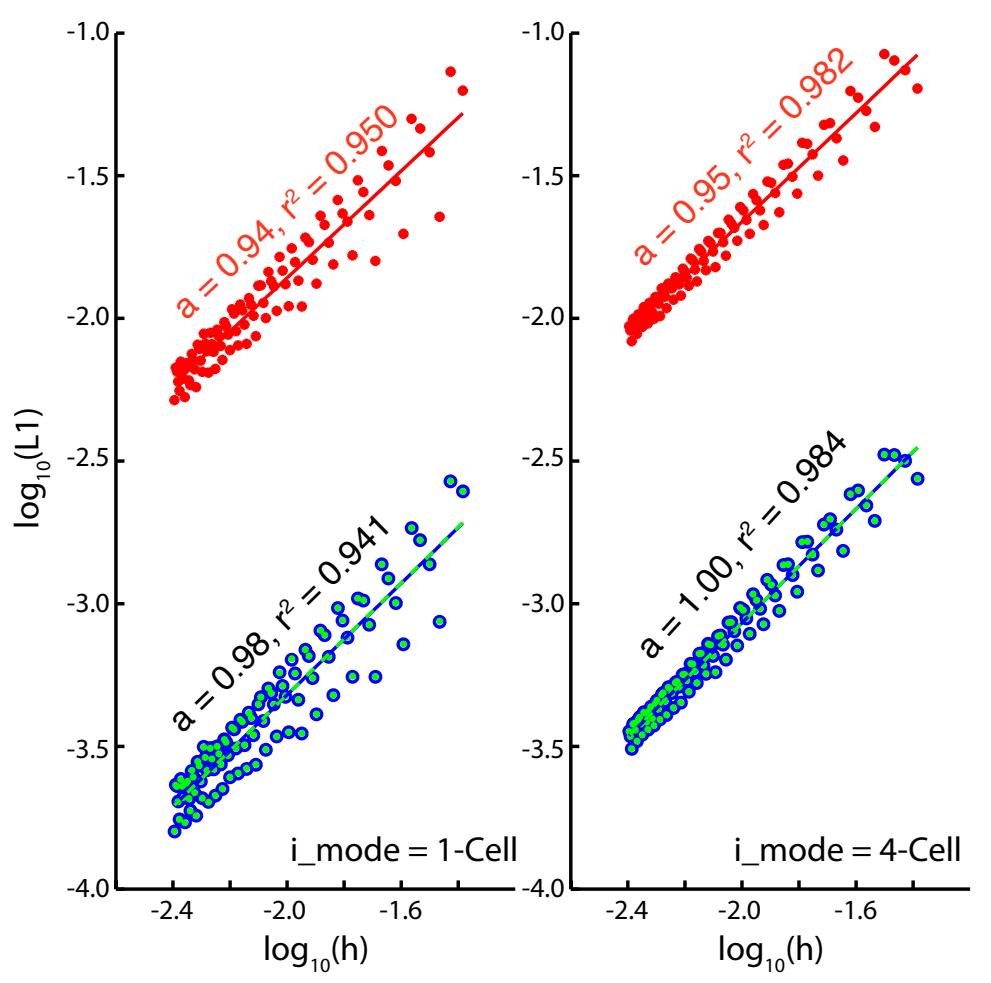




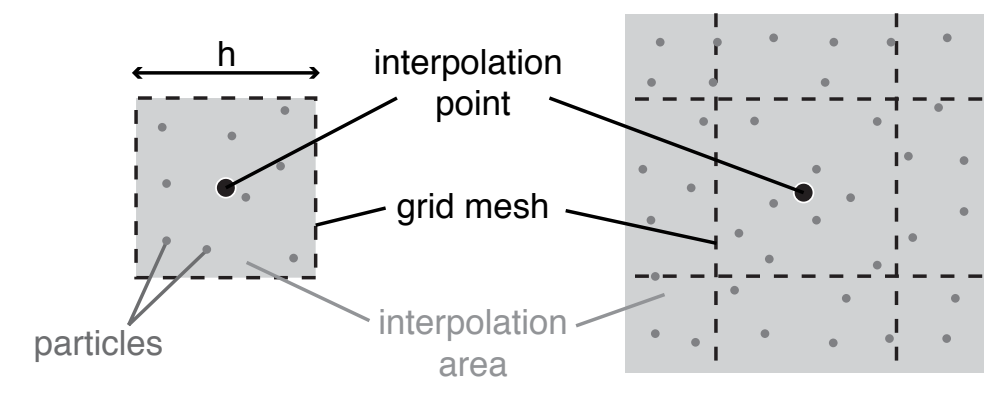




\section{$a$}

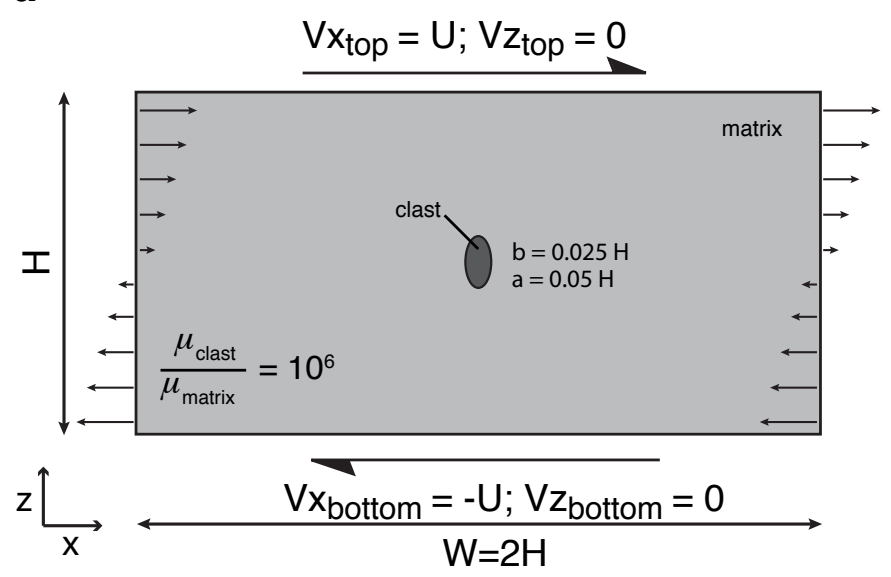

b $\quad-$ analytical solution

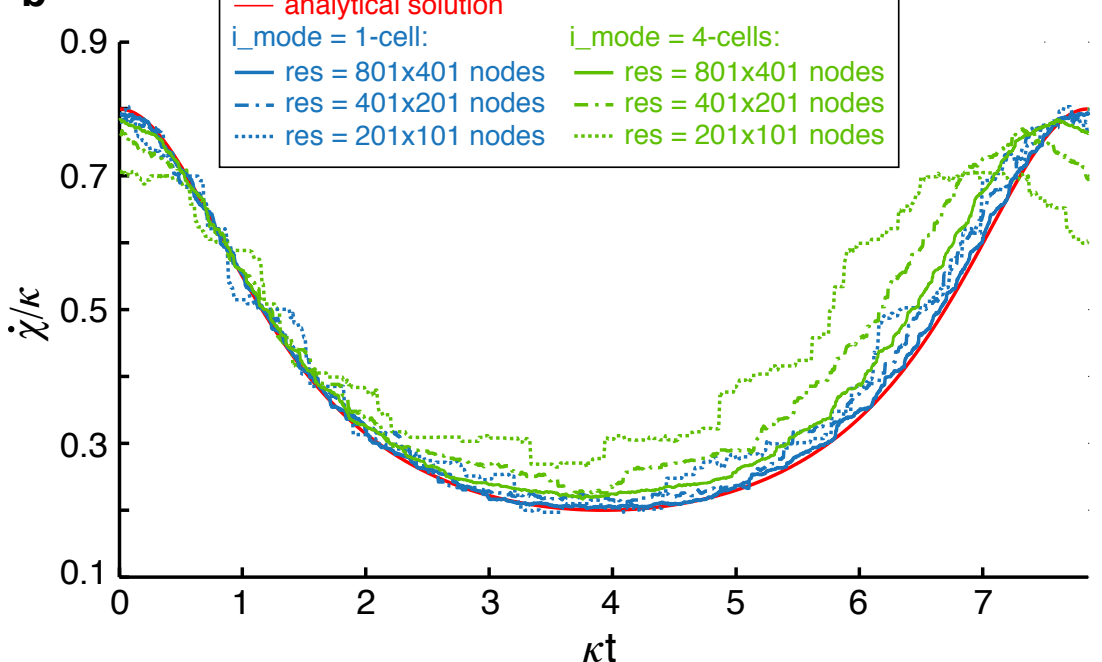

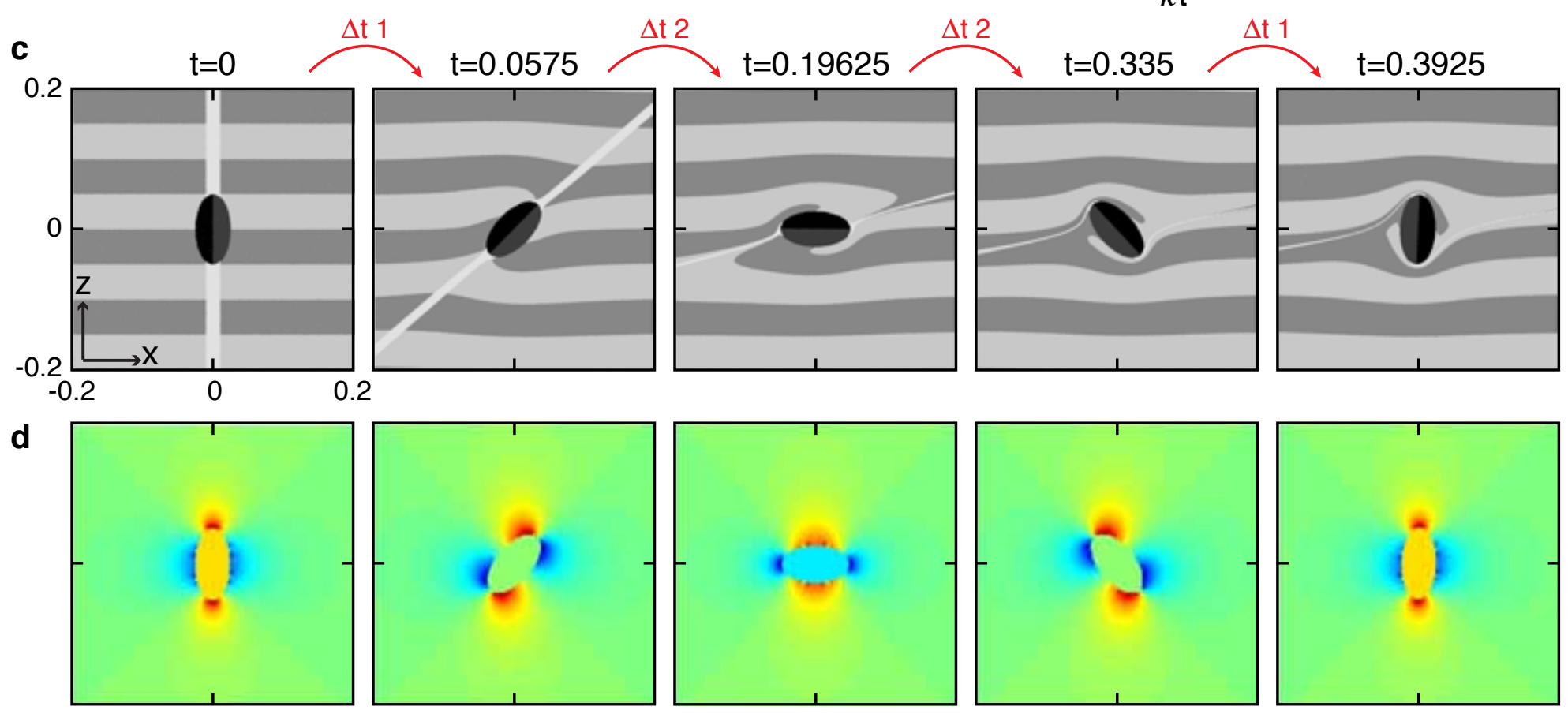

rotation rate $\left(\right.$ rad. $\left.\mathrm{s}^{-1}\right)$

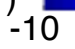

10

20

30 


\section{a}

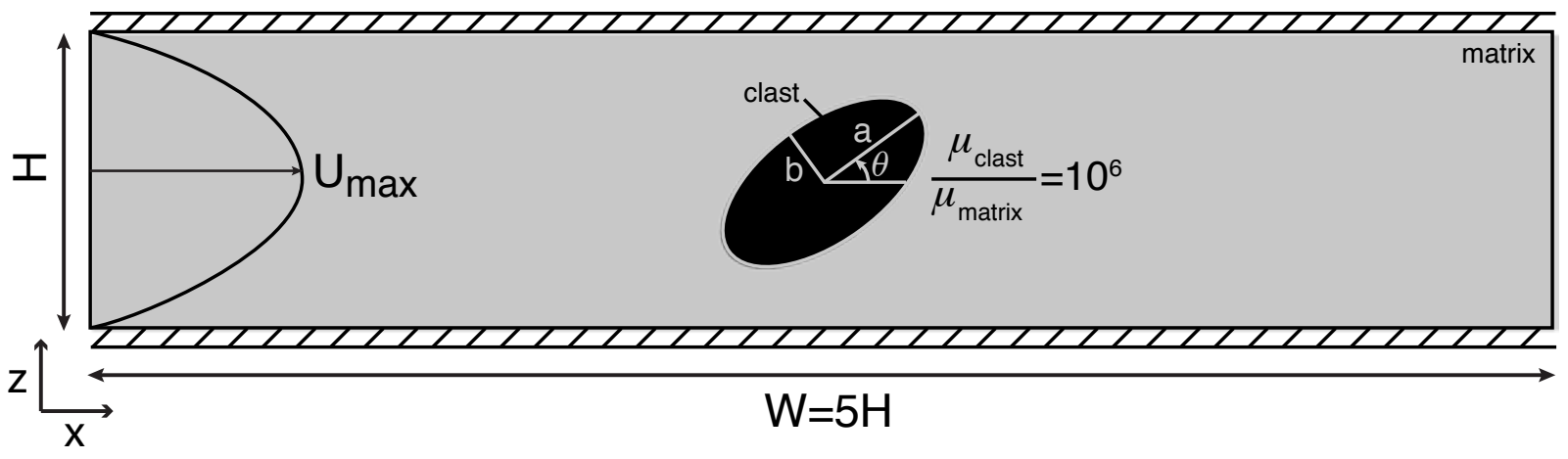

b

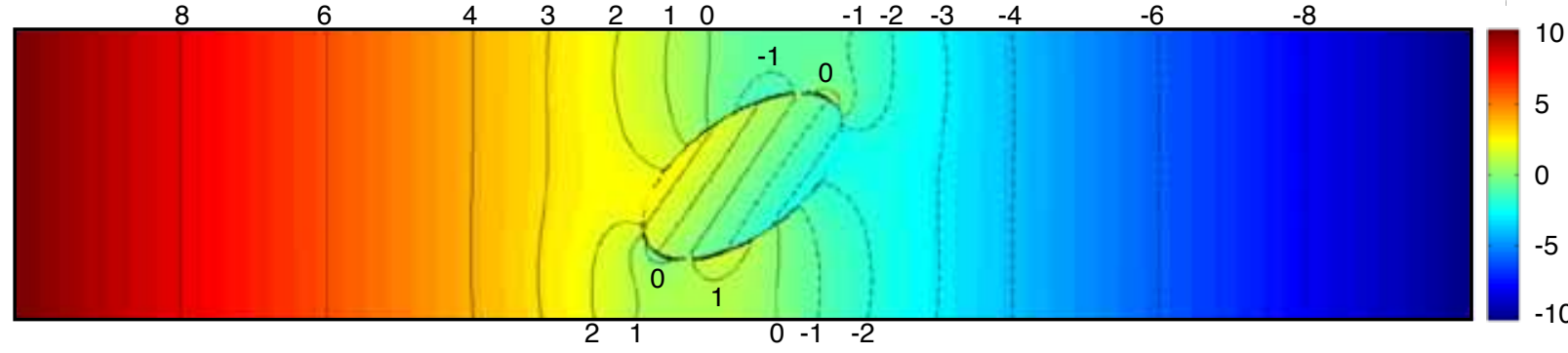




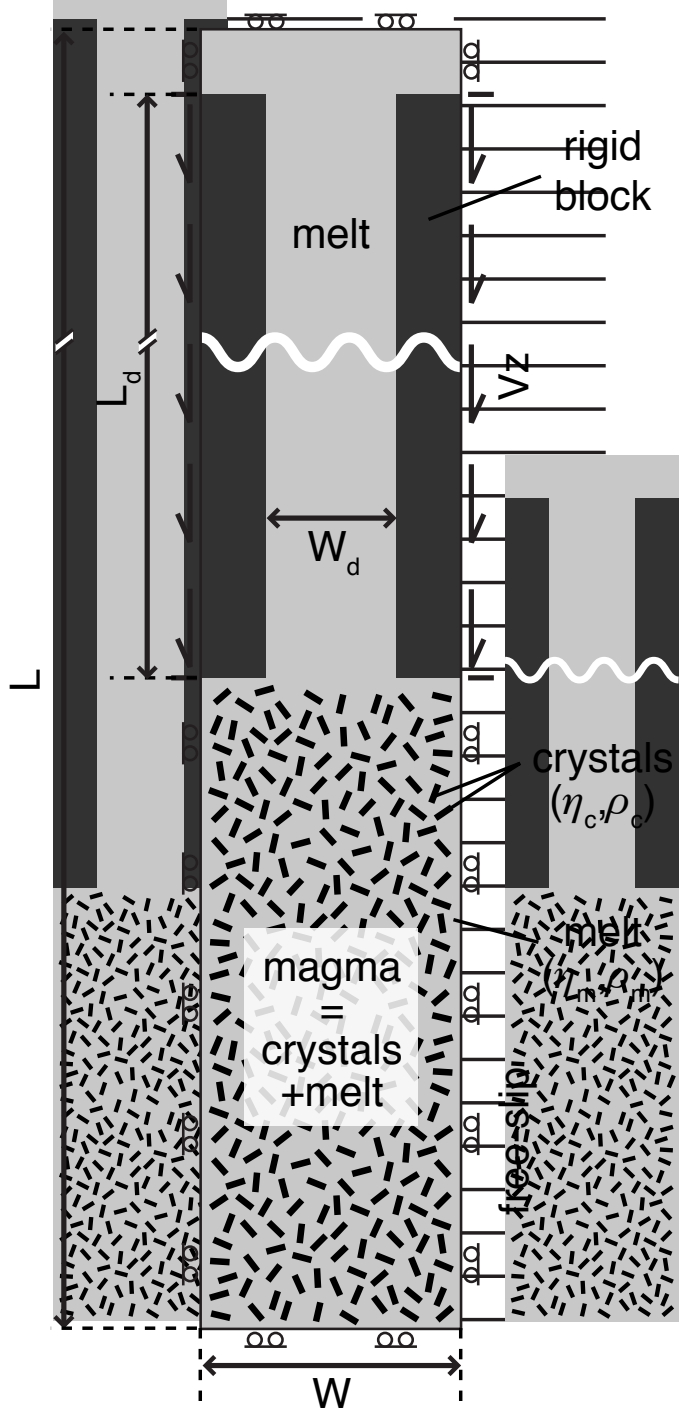




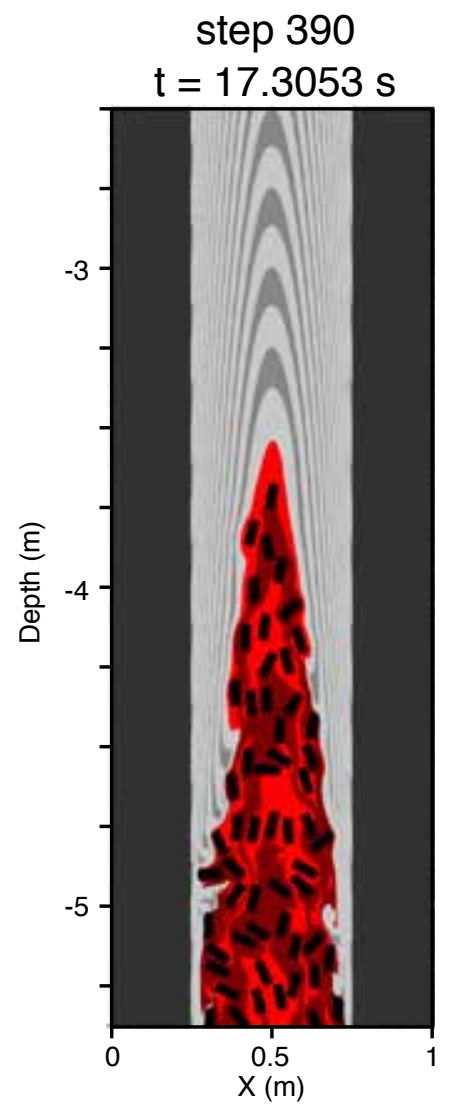

res $=775 \times 200$ step 570

$t=17.3989 \mathrm{~s}$

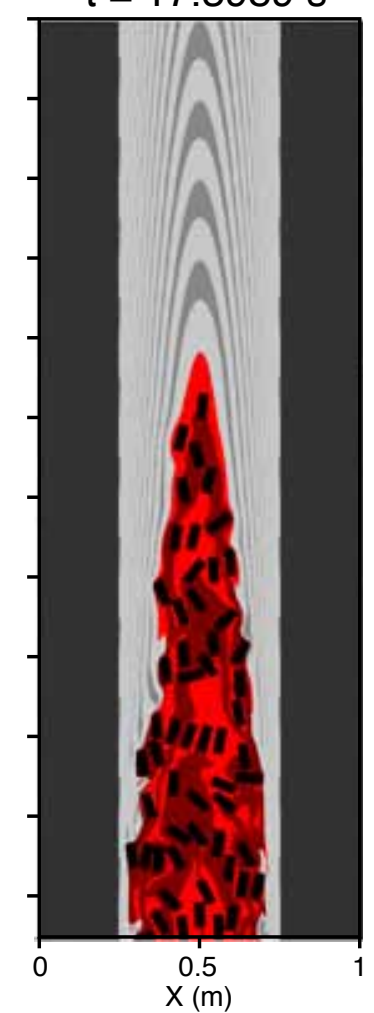

res $=1160 \times 300$ step 770

$t=17.4015 \mathrm{~s}$

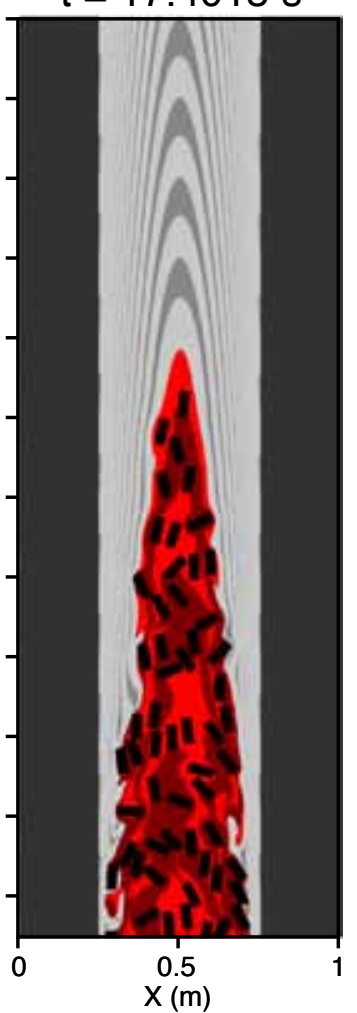

res $=1550 \times 400$ step 970

$t=17.4889 \mathrm{~s}$

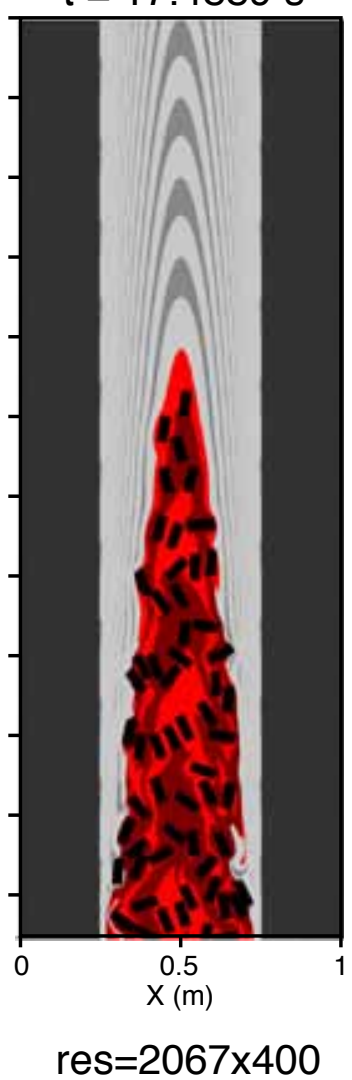


a

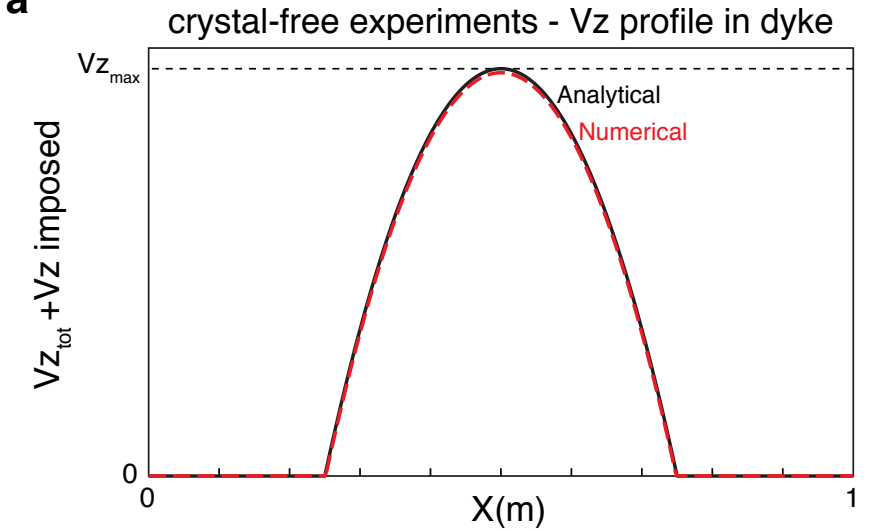

b
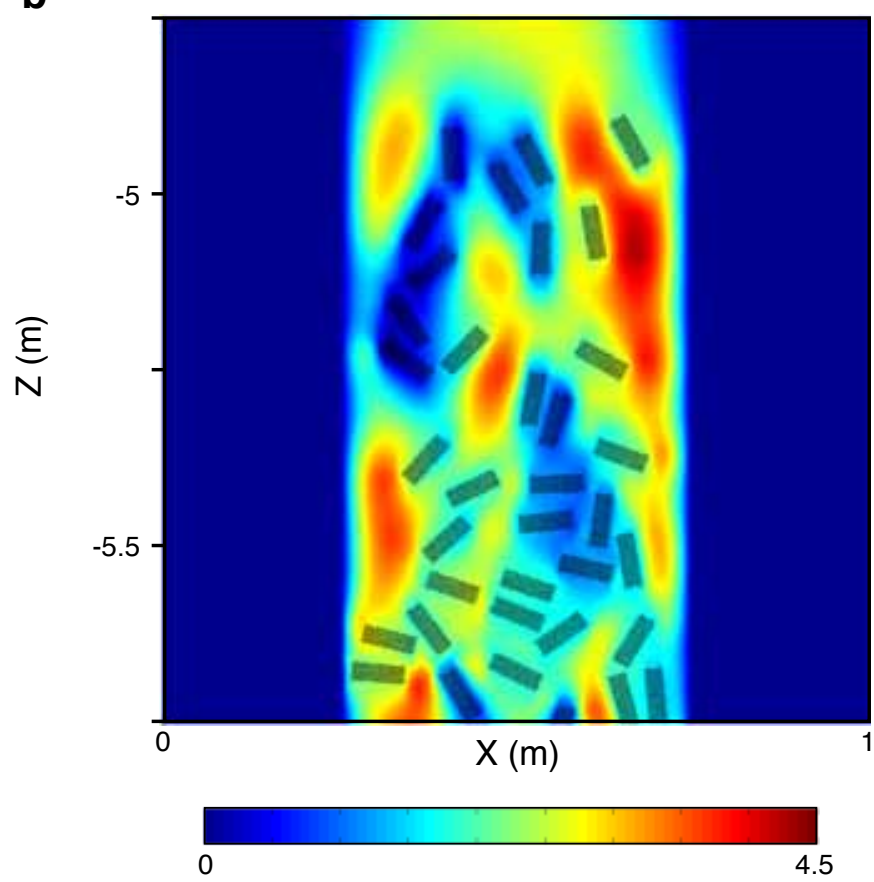

$V z_{\text {tot }}+\mathrm{Vz}$ imposed $\left(x 10^{-4}\right.$ m.s. $\left.{ }^{-1}\right)$

C

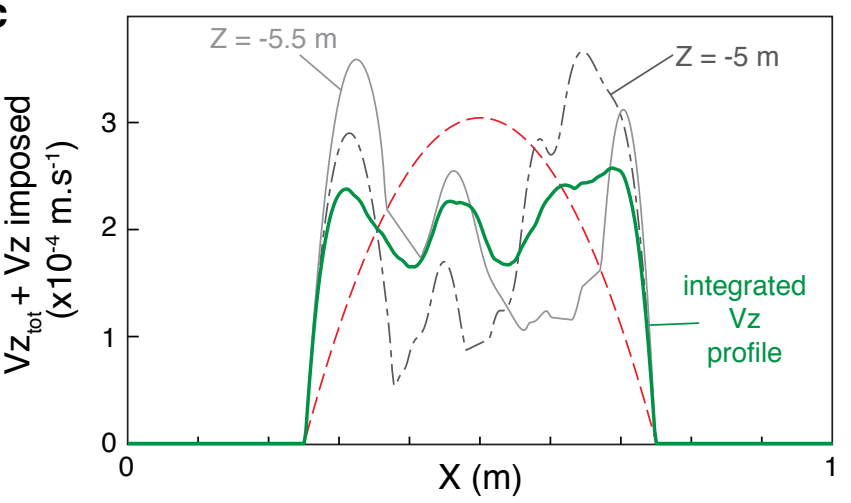



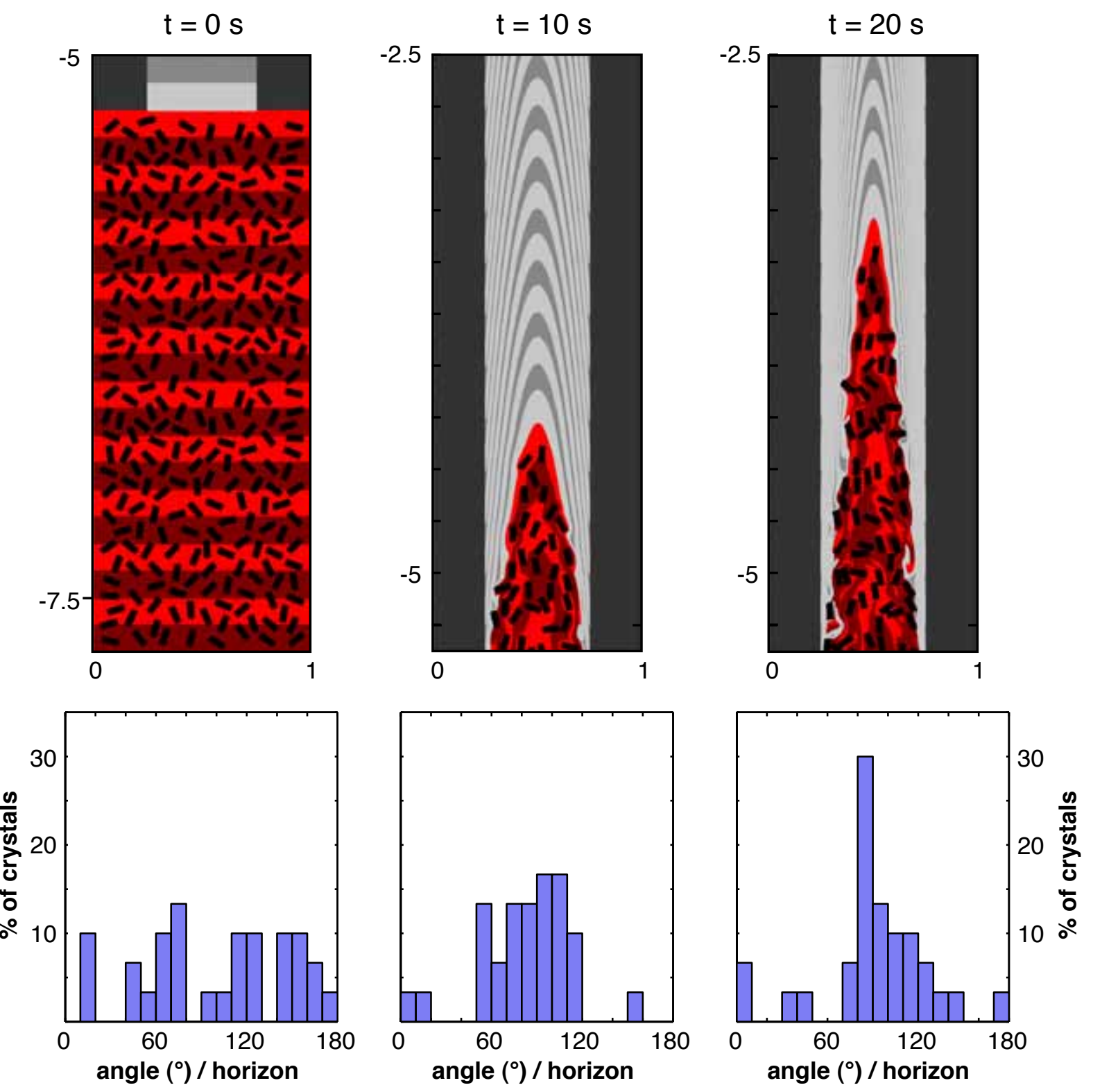


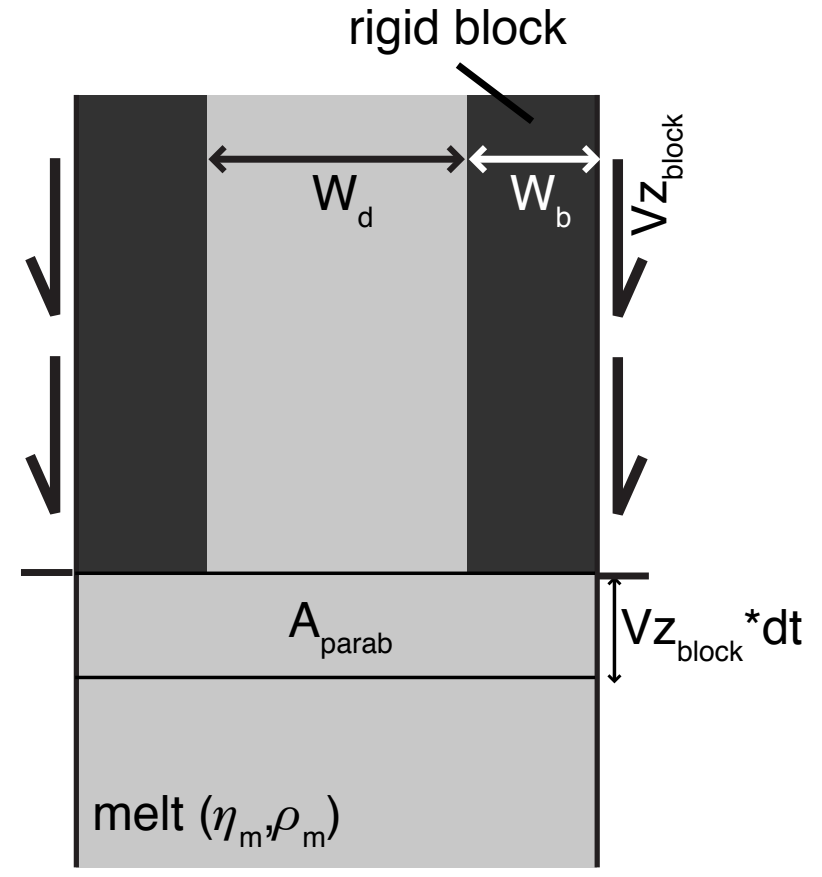

time $=t$

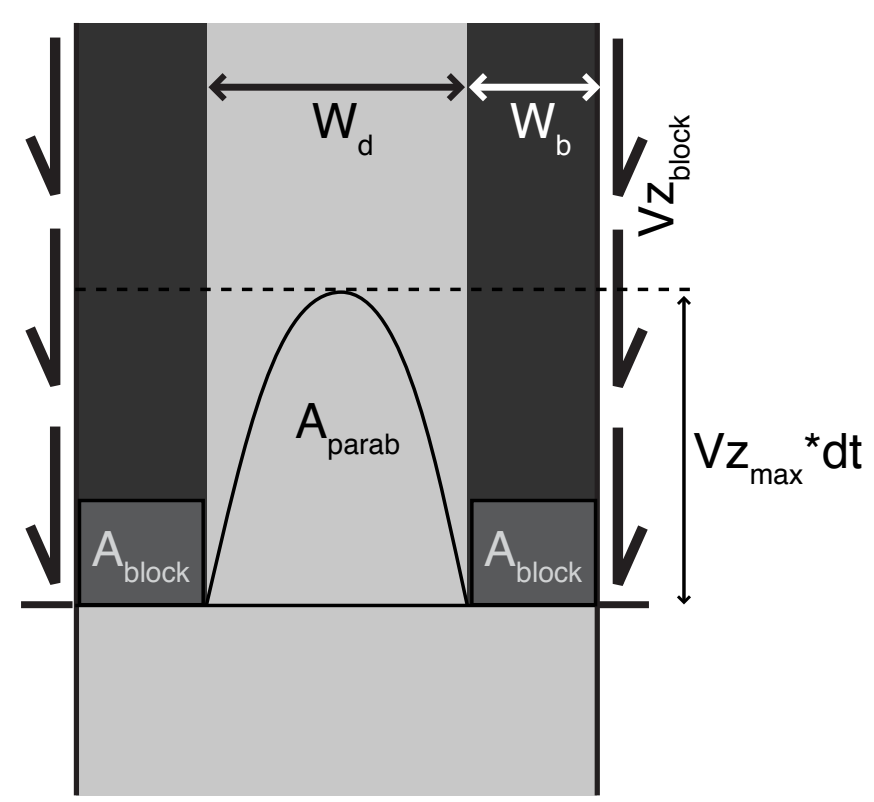

time $=t+d t$ 